\title{
Las reformas del modelo de descentralización territorial de Francia: la necesaria simplificación del «milhojas territorialı*
}

\author{
Javier Tajadura Tejada
}

DOI: https://doi.org/10.47623/ivap-rvap.108.2017.06

\begin{abstract}
Sumario: I. Introducción. - II. La organización territorial de Francia: municipios y departamentos. II.1. La supresión de las provincias y el establecimiento de los departamentos. II.2. La excesiva fragmentación municipal.-III. El surgimiento de la región: de la desconcentración a la descentralización. III.1. Primera etapa: la regionalización económica. III.2. Segunda etapa: la descentralización administrativa. III.3. Los debates sobre una nueva división regional. -IV. Las reformas territoriales de N. Sarkozy en 2010. IV.1. La clarificación competencial. IV.2. La creación de los consejeros territoriales.-V. Las reformas territoriales de F. Hollande en 2015. - VI. La creación de regiones de talla europea: la ley de 16 de enero de 2015. VI.1. Estructura y contenido del proyecto de ley. VI.2. La finalidad del proyecto: la creación de regiones de "talla europea». VI.3. Una tramitación parlamentaria muy conflictiva. VI.4. El texto definitivo de la ley. VI.5. La Decisión del Consejo Constitucional de 15 de enero de 2015. VI.6. Las elecciones regionales del 6 y 13 de diciembre de 2015. VI.7. Los Decretos del 28 de septiembre de 2016. -VII. La transferencia de competencias departamentales a las regiones: la ley de 7 de agosto de 2015. VII.1. La eliminación de la cláusula de competencia general. VII.2. EI reforzamiento del poder de las regiones en detrimento de los departamentos. - VIII. Las respuestas a la extrema fragmentación municipal. VIII.1. La creación de «nuevos municipios». VIII.2. Los establecimientos públicos de cooperación intermunicipal (EPCI). VIII.3. Las metrópolis. -IX. Conclusiones: luces y sombras de las reformas territoriales en Francia.
\end{abstract}

\footnotetext{
* Este trabajo se ha elaborado en el marco de un Proyecto de Investigación sobre "Crisis económica y reforma de las administraciones públicas» dirigido por el profesor Carlos Vidal - del que forman parte diversos profesores españoles, italianos y portugueses - y financiado por el Instituto $\mathrm{Na}$ cional de Administración Pública.
} 


\section{Introducción}

Durante su presidencia, F. Hollande ha puesto en marcha un ambicioso programa de reformas políticas y económicas. En este trabajo vamos a analizar las reformas Ilevadas a cabo en el modelo de organización territorial. Reformas político-administrativas que forman parte de un proyecto más amplio cuya finalidad primordial es la recuperación de la competitividad, el crecimiento y el empleo.

Aunque es cierto que las consecuencias de la crisis económica y financiera iniciada en 2007 se han sentido en Francia de forma atenuada - en comparación con Grecia, España, Italia o Portugal- el deterioro de sus finanzas públicas es una realidad como lo es la necesidad de impulsar el crecimiento económico, y de liberar los recursos necesarios para ello. En este contexto, en enero de 2014, el Presidente Hollande puso en marcha el denominado "Pacto de responsabilidad" que supuso un considerable recorte de los gastos de la administración y una importante rebaja a las empresas en materia de cotizaciones sociales(1). De lo que se trataba era de situar de nuevo a Francia en la senda del crecimiento económico y de hacerla más competitiva. Para ello, las medidas contempladas en el Pacto de Responsabilidad debían acompañarse de otras tendentes a modernizar y racionalizar la estructura administrativa territorial de Francia.

En relación con estas medidas, el 3 de junio de 2014, el Presidente de la República Francesa, F. Hollande, publicó - en la prensa regional del país - una tribuna en la que defendía la necesidad de llevar a cabo una ambiciosa reforma de la organización territorial de Francia y los objetivos que con dicha reforma se debían alcanzar: "Depuis deux siècles, la République a cherché à concilier l'unité de l'État, avec l'exercice le plus libre possible de la démocratie locale. (...) Le temps est (donc) venu de simplifier et clarifier pour que chacun sache qui décide, qui finance et à partir de quelles ressources. Le temps est venu d'offrir une meilleure qualité de service et de moins solliciter le contribuable tout en assurant la solidarité financière entre collectivités selon leur niveau de richesse. La réforme que j'ai demandé au Premier ministre et au Gouvernement de mettre en oeuvre, en y associant toutes les familles politiques, est majeure. II s'agit

(1) El Pacto de Responsabilidad incluía cuatro tipos de medidas: a) Eliminación de las cotizaciones sociales familiares a las empresas. b) Modernización de la fiscalidad de las empresas y disminución del número de impuestos actuales, a cambio de que haya inversiones y creación de empleo. c) Simplificación: reducción de normas y cargas administrativas. d) Contrapartidas desde el ámbito empresarial. A estos efectos, se prevé la creación de un Observatorio de seguimiento, al que estará asociado el Parlamento francés, que definirá, a nivel nacional y sectorial, objetivos de contratación, de inserción de jóvenes o personas mayores en el mercado laboral, de formación, de apertura de negociaciones sobre las remuneraciones salariales, y de modernización del diálogo social. 
de transformer pour plusieurs décennies l'architecture territoriale de la République» (2).

Estas últimas palabras ponen de manifiesto la ambición y trascendencia de las reformas que vamos a examinar en este trabajo. Con ellas se pretende «transformar para varias décadas la arquitectura territorial de la República».

Dos semanas después, el 18 de junio de 2014, el Consejo de Ministros aprobó dos proyectos de ley que introducían reformas de gran calado en la arquitectura territorial francesa:

a) El «Projet de loi portant nouvelle organisation territoriale de la République»(3). pretendía reforzar las regiones, transfiriéndoles muchas de las competencias que, hasta el momento, ejercían los departamentos. El propósito último era suprimir los departamentos en el Horizonte 2020. El proyecto se convirtió en la Ley 2015-991 de 7 de agosto de 2015.

b) El «Projet de loi relatif à la délimitation des régions, aux élections regionales et departamentales et modifiant le calendrier electoral»(4), por su parte, llevaba a cabo una profunda modificación del mapa regional, reduciendo el número de regiones para dotarlas de una "talla crítica» en cuanto a su población, territorio y recursos económicos. Se pretendía con ello mejorar la eficacia y la eficiencia de las políticas públicas. El proyecto se convirtió en la Ley 2015-29 de 16 de enero de 2015.

La necesidad de la reforma del sistema territorial francés no estaba en cuestión. La organización territorial de la República era objeto de fuertes críticas desde hacía mucho tiempo: demasiado complejo, demasiado caro, fuente de bloqueos y de retrasos...etc. (5). Con razón, el relator del Senado del proyecto de ley sobre el nuevo mapa regional, M. Delabarre,

(2) «Durante dos siglos, la República ha tratado de conciliar la unidad del Estado, con el ejercicio lo más libre posible de la democracia local. (...) Ha llegado la hora de simplificar y aclarar para que todos sepan quién decide, quién financia y a partir de qué recursos lo hace. Ha llegado el momento de ofrecer una mejor calidad de servicio y reducir la presión del contribuyente garantizando al mismo tiempo la solidaridad financiera entre las comunidades en función de su nivel de riqueza. La reforma que he pedido al primer ministro y al Gobierno que pongan en práctica, con la participación de todas las familias políticas, es importante. Se trata de transformar para varias décadas la arquitectura territorial de la República».

(3) Presentado por la Ministra de la Función Pública y de la Descentralización, Mme. Marylise Lebranchu, y por el Secretario de Estado para la reforma territorial, M. André Vallini.

(4) Presentado por el Ministro del Interior, M. Bernard Cazeneuve.

(5) En 2015, coexistían en Francia 22 regiones metropolitanas (incluyendo la colectividad territorial de Córcega) - con 1757 cargos electos - y 5 regiones de ultramar; 96 departamentos - con 4058 electos, y 5 departamentos de ultramar; 13.400 intermunicipalidades y 36.700 municipios. Francia es el país que tiene el mayor número de municipios del mundo. 
pudo afirmar con rotundidad que "el tiempo de la reforma ha llegado". La reforma persigue fijar un mapa regional ideal teniendo en cuenta los problemas de lo real. Su objetivo es la búsqueda de una acción local más eficaz, que responda a las expectativas de los ciudadanos.

La reconfiguración del mapa regional francés (de 22 a 13 regiones) se produce en un contexto de grave crisis económica y persigue también una mayor optimización de los recursos públicos. Francia transita de esta forma por la senda marcada anteriormente por otros países europeos: Polonia redujo sus regiones a 16; Grecia suprimió sus 54 provincias y las reemplazó por 13 regiones; Dinamarca reemplazó también sus 14 provincias por 5 regiones; Suecia redujo sus regiones de 21 a 10.

Para una cabal comprensión del significado y alcance de esta reforma es preciso examinar brevemente el diseño de la arquitectura territorial de Francia. La organización territorial de la República pivotó tradicionalmente sobre los municipios y departamentos y, a partir de 1982, se potenciaron las regiones sobre la base de los departamentos existentes. La evolución del sistema dio lugar a una estructura compleja (municipios, intermunicipalidades, departamentos, regiones), costosa, con duplicidades, conocido como "milhojas territorial» (6).

En este trabajo vamos a examinar el origen y evolución del modelo de organización territorial de Francia (epígrafes 2 a 4) para centrarnos después en el análisis de las reformas efectuadas durante los últimos cinco años en orden a potenciar las regiones y dotarlas de una talla crítica similar al de sus homólogas de otros Estados - como puede ser Alemania- (epígrafes 5 a 7). Expondremos también como el problema de la extrema fragmentación municipal persiste, pero ha sido afrontado mediante la potenciación de fórmulas de cooperación intermunicipal y el establecimiento de un estatuto especial para las grandes ciudades (epígrafe 8).

Siguiendo este esquema, en el siguiente epígrafe vamos a exponer brevemente la evolución del modelo territorial francés desde las Revolución hasta el inicio del proceso de descentralización regional operado en 1982.

(6) «El paisaje institucional infraestatal fue construido por sedimentación, por acumulación de estratos sucesivos. Y finalmente, el milhojas administrativo se corresponde con una red más o menos densa de competencias encadenadas, de competencias compartidas, o de competencias concurrentes entre el Estado y las entidades locales y entre esas entidades mismas. Es tan complejo que, en ciertas ocasiones, es difícil identificar quién puede intervenir». ALCARAZ, H.: "La organización territorial francesa en 2015: ¿Hacia una redefinición territorial?» en Cuadernos Gimenez Abad, núm. 10, 2015, pág. 33. "Las colectividades se superponen, y con ellas sus competencias, superponiéndose y alternándose como las capas de pasta de hojaldre y de crema del famoso postre». BLAIRON, K.: "Organización territorial en Francia: alcance de las reformas de 2010" en Revista catalana de dret public, núm. 43, 2011, pág. 349. 


\section{La organización territorial de Francia: municipios y departamentos}

\section{II.1. La supresión de las provincias y el establecimiento de los departamentos}

Uno de los objetivos prioritarios de la Revolución de 1789 fue racionalizar la compleja y abigarrada organización del Reino de Francia. La provincia - el antecedente remoto de la región - fue sustituida por el departamento que se estableció como el nuevo y principal elemento de la organización estatal.

La Revolución puso fin a los particularismos de las provincias del Antiguo Régimen. Estas se caracterizaban por usos, lenguas e instituciones comunes, y status, costumbres y privilegios particulares. Las delimitaciones territoriales de las provincias variaban con frecuencia según las épocas (7). Se trataba, en definitiva, de una organización compleja y anárquica frente a la que los diversos intentos del poder real por racionalizarla habían sido vanos. La Monarquía fracasó en su intento de unificación administrativa. Este era el escenario que se encontró en septiembre de 1789 el Comité de Constitución de la Asamblea Nacional. Una de sus misiones principales consistió en poner fin al sistema provincial y garantizar la igualdad de la representación de todos los ciudadanos. El Comité dividió Francia en 83 departamentos (8).

La delimitación de estos 83 departamentos prescindió completamente de consideraciones relativas a la supuesta "identidad regional» de los territorios (9). Junto a esta nueva división administrativa del país, subsistieron otras demarcaciones como las relativas a la percepción de impuestos o a la organización del poder judicial. Con todo, lo importante es subrayar que el departamento se concibió como el escalón racional de acción de los poderes públicos.

El municipio y el departamento son, desde la creación de los prefectos por Napoleón, las instituciones vertebradoras de la organización territorial de Francia. La primacía ha correspondido tradicionalmente al departamento.

(7) Junto a este abigarramiento de poderes particulares, existía en Francia una división entre los territorios en que se hablaba la lengua d'oc y regía un sistema jurídico inspirado en el derecho romano, y aquellos otros en los que la lengua empleada era la d'oïl et de y se regían por el derecho consuetudinario.

(8) Real Cédula expedida el 4 de marzo de 1790, tras los decretos de 15 de enero, de 16 y 26 de febrero de 1790 aprobados por la Asamblea Nacional bajo la influencia de Mirabeau.

(9) El mapa departamental se basó en un trazado racionalizado que correspondía - como subrayara Condorcet - a la distancia que podía realizar un mensajero a caballo en un solo día. 


\section{II.2. La excesiva fragmentación municipal}

El elevadísimo número de municipios es otra de las notas características del sistema francés. Esta excesiva fragmentación trae causa de la identificación llevada a cabo desde los tiempos de la Revolución entre núcleo de población y municipio (10). Los intentos de reagrupación o fusión de municipios no han tenido éxito. En el día de hoy, la República cuenta con más de 36.000 , de los cuales 28.000 tienen menos de 1000 habitantes. De ello se deriva la existencia de un mapa en el que predominan los pequeños municipios rurales que no cuentan con los medios materiales, personales y financieros necesarios para funcionar y dependen de los departamentos para mantenerse como estructuras administrativas. Esta fragmentación se ha pretendido paliar con la creación de intermunicipalidades o asociaciones de municipios, que analizaremos en el epígrafe noveno de este estudio.

Los municipios franceses presentan una doble dimensión. Por un lado, son "colectividades territoriales" o entidades locales, y por otro, se configuran como circunscripciones del Estado. En ambos casos han están sometidos durante mucho tiempo a fuertes controles por parte del poder central del Estado.

En tanto que circunscripciones del Estado, la suprema autoridad municipal, el alcalde, ha ejercido históricamente una serie de competencias como autoridad estatal (otorgamiento de licencias de construcción y mantenimiento del orden público, entre las más relevantes) siguiendo las instrucciones del prefecto. Y en cuanto entidades locales, también el ejercicio de competencias municipales propiamente dichas está sometido al control estatal. Esta situación se remonta a la época napoleónica y se refleja en el Código de Administración Municipal (1884) posteriormente denominado Código de los Municipios (1977).

El control estatal contemplaba una triple tutela. En primer lugar, la tutela administrativa en virtud de la cual todo acto administrativo municipal podía ser anulado por el prefecto(11). En segundo lugar, la tutela financiera derivada del hecho de que correspondía al Estado aprobar los presupues-

(10) Efectivamente, el mapa municipal francés se remonta a un momento muy lejano en el tiempo. El legislador revolucionario se contentó con dar el mismo estatuto municipal a las parroquias, es decir, a las circunscripciones eclesiásticas que existían ya antes de 1789 y a las ciudades que habían adquirido cierta autonomía y que se denominaban ciudades francas. La herencia de la Revolución francesa debe ser, por tanto, revaluada: a menudo se afirma que la Revolución lo barrió todo, que el mapa territorial había sido reorganizado completamente; ello es cierto respecto al departamento, que fue creado en su totalidad en lugar de las antiguas provincias; pero el mapa municipal prácticamente no ha cambiado.

(11) Aunque en la práctica, esta es una facultad que los prefectos rara vez ejercían dadas las relaciones que mantenían con los municipios. 
tos y actos de disposición patrimonial de los municipios. Y, finalmente, la denominada tutela técnica que determinaba la obligación de los municipios de obedecer todas las instrucciones y circulares procedentes de los diferentes órganos del Estado. El resultado de esta triple tutela - sobre todo la técnica - era la completa sumisión de los municipios al Estado.

Los municipios no pueden ser comprendidos al margen de su relación con los Departamentos. Estos también presentan la doble naturaleza de circunscripciones del Estado y entidades locales. Como entidades locales están administrados por un Consejo General del Departamento (12) y un Presidente ejecutivo (elegido entre los representantes locales). En teoría, la competencia del Consejo General ha sido muy amplia dado que en virtud de la cláusula de competencia general (derogada, como veremos, en 2015) podía deliberar sobre cualquier materia de su interés. En la práctica, la situación era, no obstante, muy distinta. El Presidente no podía ejecutar las decisiones adoptadas por el Consejo porque esa función correspondía al prefecto. Además, el departamento carecía de organización administrativa y no tenía órganos ni funcionarios dependientes del mismo como entidad local. Su presupuesto era elaborado y ejecutado por el prefecto. Todas las decisiones del Consejo General eran ejecutadas por los servicios estatales que dependían del prefecto.

Todo ello ha determinado durante mucho tiempo (concretamente hasta 1982, como veremos después) el predominio efectivo del poder del prefecto y la prevalencia también de forma clara de la dimensión de división o circunscripción estatal del departamento en detrimento de su condición de entidad local o colectividad territorial.

\section{El surgimiento de la región: de la desconcentración a la descentralización}

A diferencia de lo que sucede con el municipio - herencia del Antiguo Régimen-y el departamento - cuyos orígenes se remontan a la Revolución-, las regiones no hicieron su aparición hasta el final de la Primera Guerra Mundial. La región ha presentado siempre unas características distintas y una entidad mucho menor. A ello no es ajeno el hecho ya examinado de que la división en departamentos tuvo por finalidad quebrar el sistema regional propio del Antiguo Régimen(13). Las regiones fueron

(12) Cuyos miembros eran elegidos suguiendo una división del Departamento en cantones a razón de un consejero por cantón.

(13) De los diversos "mapas regionales» configurados por las sucesvas ordenaciones regionales, las antiguas regiones francesas sólo han sido tenidas en cuenta por el régimen de Vichy. En 1941 se crearon 18 prefecturas regionales, pero esas estructuras se suprimieron al concluir la guerra. 
inicialmente concebidas como un instrumento al servicio de las políticas del desarrollo económico (14) y, después evolucionaron y se convirtieron en una colectividad territorial.

La publicación en 1947 de la obra de Jean-François Gravier (19152005) "Paris et le désert français» en la que denunciaba la hipertrofia de París en detrimento del resto del territorio tuvo un amplio impacto en la opinión pública y en la clase dirigente francesa(15). Se tomó conciencia de los inconvenientes que conlleva la centralización extrema, y de las ventajas inherentes a una distribución de las actividades económicas, industriales y de servicios, por todo el territorio de la República. Esto se tradujo en la puesta en marcha de un proceso de desconcentración regional. La idea regional emergió para ser aplicada a actuaciones de política económica.

En el proceso de regionalización de la estructura territorial de Francia podemos distinguir tres etapas y varias fases. En la primera etapa, no cabe hablar de descentralización propiamente dicha sino de desconcentración y abarca desde 1955 hasta 1982. La segunda, es la del impulso del proceso de descentralización regional iniciado en 1982 y consagrado en la reforma constitucional de 2003. Las reformas de 2010, y sobre todo las de 2015 - que analizaremos en los epígrafes cuarto a séptimo de este estudio - marcarían el inicio de una nueva etapa.

\section{III.1. Primera etapa: la regionalización económica}

\section{A. LA EMERGENCIA DE LA REGIÓN: LA REGIONALIZACIÓN ECONÓMICA}

Entre 1955 y 1960 las actuaciones de ámbito regional se enmarcaron en el contexto de la política económica. Así se crearon las regiones de programa, denominadas desde 1960 circunscripciones de acción regio-

(14) Un arrêté du 5 avril 1919 de Etienne Clémentel, Ministro de Comercio e Industria, creó las "agrupaciones de intereses regionales" - llamadas también "régions Clémentel» - cuya misión era la coordinación de los actores económicos. Inicialmente fueron creadas 15: Lille, Amiens, Rouen, Caen, Nantes, Rennes, Limoges, Bordeaux, Toulouse, Montpellier, Marseille, Grenoble, Lyon, Nancy, Paris. A ellas se sumó Dijon en 1920 y Bourges en 1921 Estas «regiones económicas" se apoyaban sobre las estructuras de las Cámaras de Comercio según el principio de libre adhesión de estas últimas. Cada agrupación era administrada por un comité regional integrado por dos delegados de cada una de las Cámaras y por los prefectos y subprefectos que tenían voz, pero no voto. Este modelo sirvió para que, en septiembre de 1919, las federaciones de sindicatos d'initiative formaran 19 regiones turísticas. En 1926 aparecieron 17 regiones postales. Después 12 regiones radiofónicas. Y en 1935, 15 regiones de seguridad social. Se trata de un regionalismo funcional, antecedente del regionalismo económico posterior a la segunda guerra mundial.

(15) GRAVIER, J. F.: Paris et le désert français, Flammarion, Paris, 1947. 
nal (16). Tras el reconocimiento como región de la Isla de Córcega (17), la nueva estructura regional estaba integrada por 22 regiones(18). Desde entonces no se ha llevado a cabo ninguna alteración del número ni de los límites territoriales de las regiones. Esto pone de manifiesto la transcendencia histórica de la reforma de 2015 que luego examinaremos. En todo caso, conviene subrayar la relevancia de estas circunscripciones - de acción regional- por ser la primera vez que se establecen regiones que no se corresponden con las antiguas delimitaciones provinciales. Las delimitaciones de los programas de acción regional prefiguraron el mapa regional que estuvo vigente en Francia hasta el 1 de enero de 2016. El mapa regional francés procede, por tanto, de aquella época, y ha estado vigente durante seis décadas. Las regiones eran el ámbito territorial en el que se desarrollaban las políticas económicas y posteriormente se les otorgó competencias en materia de ordenación del territorio. Su importancia real obedecía al hecho de que en el contexto regional era donde se llevaba a cabo la distribución de los créditos estatales para inversiones públicas.

Fue así como surgieron las regiones como entidades desconcentradas del Estado (19). En este contexto, en 1964, se introdujeron importantes novedades.

\section{B. LAS REFORMAS DE 1964}

En 1964 se dotó a las regiones de la estructura administrativa necesaria para la elaboración y ejecución de los planes económicos.

Las circunscripciones de acción regional tienen al frente un prefecto de la región, instituido por el Decreto $n .^{\circ}$ 64-250 de 14 de marzo de 1964, relativo a los poderes de los prefectos, a la organización de los servicios del Estado en los departamentos y a la desconcentración administrativa(20). Se

(16) El Decreto N . ${ }^{\circ} 55-873$, de 30 de junio de 1955 sobre el establecimiento de los programas de acción regionales, conocido como "décret Pfimplin», puso en marcha los programas de acción regionales para "favorecer la expansión económica y sociale de las regiones".

(17) Que inicialmente estaba agrupada con la región de Provenza-Alpes-Costa Azul.

(18) Una orden del Ministerio de de Economía y Finanzas del 6 de diciembre 1956 definió las veinticuatro circunscripciones de estos programas regionales de acción: veintidós áreas metropolitanas, los departamentos de ultramar y Argelia. El decreto n. ${ }^{\circ}$ 60-516 de 2 de junio de 1960 delimitó las regiones sobre las cuales se instauraron los programas de acción regional: regiones de programa.

(19) No cabe hablar en este contexto de descentralización sino únicamente de desconcentración, una técnica que permite a los agentes del poder central colocados a la cabeza de la estructura administrativa regional tomar ciertas decisiones relativas a la preparación y ejecución del plan.

(20) El prefecto regional es el prefecto del departamento donde se encuentra la ciudad capital de la región. 
creó también la Conferencia regional integrada por los prefectos del área. EI Prefecto y la Conferencia ejercían las funciones estatales ejecutivas.

De la misma forma, se estableció en cada una de las regiones, una comisión de desarrollo económico regional (CODER). Esta se configuraba como una asamblea consultiva integrada por representantes de sectores económicos y profesionales (50 por ciento) y por personas designadas por los consejos generales de las colectividades territoriales (25 por ciento) y el Primer Ministro (25 por ciento). La CODER asistía al prefecto para coordinar las actuaciones del Estado en la región. Esta organización regional estuvo vigente hasta 1972. Sobre estas bases se desarrollará años después la región como colectividad territorial.

Finalmente, el Decreto n. ${ }^{\circ} 70-18$ de 9 de enero de 1970 modificó el anexo i del decreto n. ${ }^{\circ} 60-516$ de 2 de junio de 1960 y fijó en 22 el número de regiones metropolitanas.

\section{El Referéndum del 27 dE ABRIL DE 1969}

De Gaulle pretendió dar un impulso mayor al proceso de regionalización. El objeto esencial de la ley que fue sometida a referéndum el 27 de abril de 1969 era la institución de las regiones como entidades locales dotadas de varias funciones y con órganos específicos. Su objetivo era contribuir al desarrollo económico, social y cultural de la parte correspondiente del territorio nacional. La región - según el proyecto gauIlista - era administrada por Consejos regionales no elegidos directamente por el pueblo sino en segundo grado. Estos consejos deberían estar compuestos por los diputados de la Asamblea elegidos en esa región, por los consejeros regionales territoriales elegidos por los consejos generales y municipales y por consejeros regionales socio-profesionales designados por organismos representativos. El Consejo regional debía definir, en el marco del Plan nacional, las perspectivas de desarrollo de la región y ejecutar los programas plurianuales que concernieran a la región.

El proyecto fue rechazado en referéndum, y el General de Gaulle -a consecuencia de esa derrota - abandonó el poder.

D. LA LEY DE 5 DE JULIO DE 1972: LA TRANSFORMACIÓN DE LAS REGIONES EN "ÉTABLISSEMENT PUBLIC»

Su sucesor, G. Pompidou, no quiso ir tan lejos, pero dio un limitado impulso a la regionalización. Las antiguas circunscripciones regionales fueron sustituidas por 22 regiones mediante el Decreto de 9 de enero de 
1970. La ley n. ${ }^{\circ}$ 72-619 de 5 de julio de 1972 convirtió las regiones en establecimientos públicos territoriales dotados de personalidad jurídica. De esta forma, la región -que mantiene su condición de circunscripción estatal - se convierte en un establecimiento público regional administrado par un consejo regional asistido por un comité económico y social. Las delimitaciones territoriales de estos establecimientos regionales son los que estaban en vigor desde 1956 con sus modificaciones posteriores. Esta ley estableció como órganos propios de la región los siguientes:

a) El consejo regional integrado por los diputados y senadores elegidos en la región, representantes de las colectividades locales elegidos por los consejos generales y representantes de municipios de más de 30.000 habitantes y comunidades urbanas. El consejo regional -a diferencia de su antecesor- disponía de cierto poder decisorio (por ejemplo, en materia de equipamientos colectivos) además de ser órganos consultivos en lo que a desarrollo regional se refiere.

b) El Comité económico y social integrado por miembros no electivos y con funciones meramente consultivas.

Las competencias de los establecimientos públicos regionales comprendían las materias de planificación económica y desarrollo regional.

\section{III.2. Segunda etapa: la descentralización administrativa. De la Ley de 2 de marzo de 1982 a la reforma constitucional de 2003: la conversión de las regiones en ucolectividades territoriales»}

La regionalización, entendida como un verdadero proceso de descentralización administrativa $-y$ no de mera desconcentración $(21)-$, comenzó en 1982 y se justificó por la necesidad de adaptar la República a los nuevos programas y a las políticas a escala regional diseñados en el

\footnotetext{
(21) La desconcentración supone la integración jurídica de todos los servicios en el seno de una única entidad jurídica que es el Estado. Los servicios locales no son autónomos y están jerárquicamente subordinados a los servicios centrales. La Constitución consagra la desconcentración en el art. 72. 6: "El representante del Estado, que lo es también de cada uno de los miembros del Gobierno, velará por los intereses nacionales, el control administrativo y el respeto a las leyes». El departamento es el nivel más significativo donde el Estado está representado por el prefecto. Los agentes desconcentrados ejercen sus competencias en circunscripciones administrativas sin personalidad jurídica. Las colectividades territoriales - municipio, departamento y región - que son también circunscripciones administrativas constituyen el marco de la desconcentración. Con las últimas reformas administrativas se ha antepuesto la fiugura del prefecto de la región (que lo es el del departamento donde tenga su capitalidad la región) en detrimento del prefecto departamental.
} 
marco de las Comunidades Europeas (Política agrícola común, Fondo Social Europeo, fondos y programas de cohesión, etc.) (22).

El artículo 72 de la Constitución francesa establecía en ese momento lo siguiente: "Las colectividades territoriales de la República son los municipios, los departamentos y los territorios de ultramar. Cualquier otra colectividad territorial debe ser creada por ley». En virtud de esta disposición habilitante, en 1982, el legislador dotó a las regiones del estatuto de colectividades territoriales (23).

La ley $n .^{\circ} 82-213$ de 2 de marzo de 1982 relativa a los derechos y libertades de los municipios, departamentos y regiones sentó las bases de la regionalización política francesa(24). A dicha ley se le atribuyó el efecto de transformar la República jacobina en una República descentralizada. La desconcentración dió paso a la descentralización.

En todo caso, conviene subrayar que, las nuevas regiones (25), promovidas por la ley al rango de colectividades territoriales tal y como autorizaba la Constitución, no participan de un grado de descentralización similar al de las regiones italianas o al de nuestras Comunidades Autónomas (26). Las diferencias son notables, y no meramente cuantitativas sino de índole cualitativa. Las regiones francesas $-y$ esto resulta esencial subrayarlo - carecen de poder legislativo y de poder reglamentario propio. Atribuir a las regiones estos poderes exigiría modificar los artículos 34 y 37 de la Constitución que reservan al Parlamento y al Gobierno de Francia el ejercicio del poder legislativo y reglamentario general. Si tomamos como criterio diferenciador de un regionalismo político distinto del mero regionalismo administrativo la atribución a la región de un poder normativo propio, la inexistencia del mismo en las regiones francesas nos conduce a calificar el regionalismo francés como administrativo.

(22) PONTIER, J. M.: "Le rôle des collectivités territoriales dans la construction européenne» en Revue administrative, núm. 333, Paris, 2003, págs. 277 y ss. FOUGEROUSE, J.: "La consecration constitutionnelle des regions françaises: l'emergence d'un modèle original intégré au concert européen" en Revue Générale des Collectivités Territoriales, núm. 28, Paris, 2003, págs. 616 y s.

(23) La descentralización era uno de los objetivos prioritarios del programa del Partido Socialista Francés y a ella se referían también algunas de las 110 propuestas para Francia con las que F. Mitterrand se presentó a las elecciones presidenciales que ganó en 1981.

(24) Fue modifuicada en ciertos aspectos por la ley de 22 de julio de 1982 redactada para acomodarla a la decisión del Consejo Constitucional de 25 de febrero de 1982. Se trata del denominado ACTO I de la descentralización (leyes Deferre).

(25) Nuevas en cuanto a su status no en cuanto a sus límites territoriales, pues estos no habían experimentado cambios.

(26) GREMION, C.: «Région, département, commune: le faux débat» en Pouvoirs, núm. 60, 1992, Págs. 55-65. 
Precisado lo anterior, lo que importa es subrayar las importantes novedades que la ley introdujo en el sistema territorial de Francia:

a) En primer lugar, la consagración de la región como una colectividad territorial (entidad local) de pleno derecho, con el mismo título que los municipios y los departamentos.

b) En segundo lugar, la supresión de la tutela administrativa Ilevada a cabo por los prefectos. Los actos y decisiones de las colectividades territoriales se aplican en cuanto son publicados. En el caso de que el Prefecto considere que un acto de una colectividad territorial es ilegal, debe impugnarlo ante el tribunal administrativo.

c) En tercer lugar, la transferencia del poder ejecutivo a los departamentos y a las regiones. Antes, el prefecto era el encargado de aplicar las decisiones adoptadas en los ámbitos departamental y regional. Ahora el poder ejecutivo se atribuye al presidente del consejo general (en el Departamento) y del consejo regional (en la Región.

d) En cuarto lugar, la elección por sufragio universal directo de los miembros del Consejo regional - en el marco de circunscripciones departamentales y según un sistema de representación proporcional- por un mandato de 6 años renovable (27).

e) Finalmente, la atribución a las regiones de una serie de competencias específicas.

En el marco de este proceso de descentralización iniciado en 1982 se aprobaron diversas e importantes leyes (28):

- Leyes de 7 de enero y de 22 de julio de 1983 que otorgan competencias concretas a las regiones.

- Ley de 10 de julio de 1985 sobre la elección de los consejeros regionales.

- Ley de 6 de enero de 1986 sobre la organización de las regiones.

- Ley de 5 de enero de 1988 relativa al perfeccionamiento de la descentralización.

\footnotetext{
(27) Las primeras elecciones regionales - reguladas por la ley núm. 85-692 de 10 de julio de 1985 de modificación del Código electoral y relativa a la elección de consejeros regionales - tuvieron lugar el 16 de marzo de 1986. Después se han celebrado en 1992, 1998, 2004, 2010 y 2015 (como consecuencia de la reducción excepcional de su mandato a cuatro años por ley de 2011, y de la posterior modificación del calendario electoral incluida en la Ley de 16 de enero de 2015). En 2003 se llevó a cabo una modificación del sistema electoral para favorecer la formación de mayorías estables y se elevó del 5 al 10 por ciento el número de votos para pasar a la segunda vuelta. MALIGNER, B.: "La loi du 11 avril 2003 et la réforme des élections regionales» en Bulletin juridique de collectivités locals, n. ${ }^{\circ} 9,2003$, págs. 20 y ss.
}

(28) Resulta significativo que entre 1981 y 1986 el Ministro del Interior lo fuera «Del Interior y de la Descentralización». 
- Ley de 13 de mayo de 1991 del Estatuto de Córcega. Dota a esta región de un estatuto de colectividad territorial particular en el sentido del artículo 72 de la Constitución (29).

- Ley de 6 de febrero de 1992 sobre la administración territorial de la República.

De acuerdo con el artículo 59 de la ley de 2 de marzo de 1982 y con el artículo 4 de la ley de 6 de enero de 1986, el Consejo regional dirige mediante sus deliberaciones los asuntos de la región. Extiende su competencia a la promoción del desarrollo económico, social, sanitario y cultural y científico de la región y a la conservación de su identidad, en el respeto a la integridad, autonomía y atribuciones de los departamentos y municipios. El Consejo participa en la elaboración y ejecución del Plan nacional y elabora y aprueba el Plan regional. El legislador configuró así la región como el núcleo básico de la descentralización económica.

El presidente del Consejo Regional encarna el gobierno de la Región. Elegido por el Consejo, por un mandato de 6 años, prepara y ejecuta el presupuesto, ordena los gastos, gestiona el patrimonio regional, ejerce el mando jerárquico sobre los servicios regionales y convoca las sesiones del Consejo.

Junto al Consejo regional y su Presidente, el otro órgano específico de la región es el Consejo económico y social regional. Estos órganos fueron instituidos por la ley de 6 de enero de 1986 con la denominación de Comités económicos y sociales y en 1992 (ley de 6 de febrero de 1992) pasaron a llamarse Consejos económicos y sociales. Sus funciones son meramente consultivas. Su composición es la siguiente: un 35 por ciento de sus miembros representan a empresarios y profesionales no asalariados; otro 35 por ciento a organizaciones sindicales de asalariados y a la Federación de educación nacional; un 25 por ciento a organizaciones que participan en la vida regional; y el 5 por ciento restante lo integran personalidades que han contribuido al desarrollo de la región.

Los regionalistas ganaron así la batalla a los departamentalistas. La ley de 7 de enero de 1983 atribuyó a las regiones el poder de decisión y a los municipios y departamentos el derecho a ser consultados previamente a la decisión. Ese mismo año se transfirieron a las regiones competencias en materia de sanidad, bienestar social, transportes, educación y cultura.

Este nuevo modelo territorial - cuyo marco normativo viene fijado por las leyes anteriormente expuestas - fue incorporado a la Constitución en

(29) El Consejo Constitucional en su importante decisión de 9 de mayo de 1991 declaró que la referencia del legislador al "pueblo corso" es inconstitucional puesto que la Constitución no reconoce la existencia de ningún pueblo distinto del francés, integrado éste por todos los ciudadanos franceses, sin distinción de origen, raza o religión. 
2003 mediante la ley constitucional núm. 2003-276 de 28 de marzo, relativa a la organización descentralizada de la República para que las regiones sean inscritas en el artículo 72 de la Constitución como colectividades territoriales con el mismo rango que los otros dos niveles existentes: municipios y departamentos (30). Por primera vez, las regiones integran esta enumeración constitucional de las colectividades territoriales. Se establece así una garantía institucional para estas categorías que sólo podrán ya ser suprimidas por reforma constitucional (31).

Ahora bien, las colectividades territoriales no gozan de autonomía. El Derecho francés utiliza el término de "libre administración». Así el párrafo tercero del citado artículo 72 de la Constitución precisa que: «En las condiciones previstas por la ley, estas entidades se administran libremente a través de consejos electos".

La libre administración es un principio de valor constitucional (32) que viene definido por las dos notas contenidas en el art. 72. 3(33), a saber:

a) La primera, de tipo institucional, implica que la libre administración se ejerce "por consejos electos». Esto supone la elección por sufragio universal de los órganos deliberantes de la colectividad dota-

(30) En virtud de esa reforma el artículo 1 de la Constitución dispone que «la organización de la República es descentralizada». La reforma constitucional de 2003 se conoce como el ACTO II de la descentralización. ZOCO, C.: «Revisión constitucional en Francia: la redefinición del modelo de descentralización administrativa» en Revista Española de Derecho Constitucional, núm. 72, 2004, págs. 163 y ss.

(31) Artículo 72 de la Constitución francesa: "Las entidades territoriales de la República son los municipios, los departamentos, las regiones, las entidades con estatuto particular y las entidades de Ultramar regidas por el artículo 74. Cualquier otra entidad territorial se crea por ley, en su caso, en lugar de una o de varias de las entidades mencionadas en este apartado. Las entidades territoriales podrán decidir sobre el conjunto de las competencias que mejor pueden ejercerse a sus respectivos niveles. En las condiciones previstas por la ley, estas entidades se administran libremente a través de consejos elegidos y disponen de un poder reglamentario para ejercer sus competencias. En las condiciones previstas por la ley orgánica, y salvo que se trate de las condiciones esenciales para el ejercicio de una libertad pública o de un derecho garantizado por la Constitución, las entidades territoriales o agrupaciones podrán, cuando esté previsto por la ley o por el reglamento, derogar, a título experimental y para una duración y fin limitados, las disposiciones legislativas o reglamentarias que rigen el ejercicio de sus competencias. Ninguna entidad territorial podrá ejercer una tutela sobre otra. Sin embargo, cuando el ejercicio de una competencia necesite la ayuda de varias entidades territoriales, la ley permite que una de esas entidades o agrupaciones organice las modalidades de su acción común. En las entidades territoriales de la República, el representante del Estado, que lo es también de cada uno de los miembros del Gobierno, velará por los intereses nacionales, el control administrativo y el respeto a las leyes. VERPEAUX, M.: "La loi constitutionnelle du 28 mars 2003 relative à l'organisation décentralisée de la Republique: libres propos» en Revue Française du Droit Administrative, núm 4, 2003.

(32) Decisión del Consejo Constitucional núm. 79-104, de 23 de mayo de 1979. FAVOREU, L., ROUX, A.: "La libre administration des collectivités territoriales est-ele une liberté fondamentale?» en Les cahiers du Conseil constitutionnel, núm. 12, http://www.conseil-constitutionnel.fr/cahiers/ccc12/ ccc12somm.htm.

(33) BLAIRON, K.: «Organización territorial en Francia...ob. cit. pág. 348. 
dos de "atribuciones efectivas». Cada colectividad territorial -municipio, departamento y región - dispone así de dos instituciones propias: una asamblea deliberante y un ejecutivo.

b) La segunda, de tipo normativo, supone la atribución de un poder reglamentario a estas colectividades. Se trata de una potestad reglamentaria condicionada por la ley que es la que, en última instancia, determina las competencias de las colectividades y las modalidades de su ejercicio.

A todo ello habría que añadir que la Constitución proyecta el principio de igualdad a las colectividades territoriales mediante la interdicción de la tutela de un ente territorial sobre otro (art. 72. 5 de la Constitución).

\section{III.3. Los debates sobre una nueva división regional}

La exposición anterior sobre los orígenes y evolución del sistema territorial francés nos permite comprender el sentido y alcance de la reforma operada en 2015-2016. Una reforma que culmina un proceso de debate político iniciado pocos años después de la inclusión del hecho regional en la Constitución de la V República.

En la primera década de este siglo surgieron numerosas reflexiones sobre la división de las regiones, sobre su número ideal, así como sobre sus recursos y su superficie. En 2009, el Comité para la reforma de las colectividades locales - presidido por el antiguo Primer Ministro, E. Balladur - propuso reducir a quince el número de regiones. Esta reconfiguración o redistribución regional debía acompañarse de una redefinición de las competencias de los departamentos y de las regiones. Las conclusiones de este comité se apoyaban sobre las de la comisión para la libération de la croissance française - presidido por J. Attali, que proponían la supresión de los departamentos en beneficio de las regiones, con el fín de simplificar la "millefeuille administratif». Aunque circularon muchos mapas regionales, el informe del comité Balladur -entregado al Presidente de la República el 5 de marzo de 2009 (34) - no contenía ninguna propuesta concreta.

a) La Comisión Atali (2008)

El Presidente Sarkozy encargó a una Comisión presidida por Jacques Attali la elaboración de un informe para relanzar el crecimiento econó-

(34) Que llevaba un título muy significativo: "Il est temps de décider». ("Es hora de decidir»). 
mico de Francia. La Comisión comenzó sus trabajos en junio de 2007 y entregó su informe el 23 de enero de 2008(35). Una de las principales medidas sugeridas por la Comisión era la simplificación de la organización territorial francesa para aumentar su eficacia. Para ello defendía la potenciación de las regiones, la transformación de las intermunicipalidades en "aglomeraciones", entidades de rango constitucional, y la supresión en diez años del escalón departamental. Todo ello acompañado de una clarificación de las competencias de cada colectividad.

El informe abogaba por una organización territorial de dos niveles: por un lado, un número reducido de regiones de suficiente potencia económica; y, por otro, las intermunicipalidades cuya población debía oscilar según la Comisión entre los 60.000 y los 500.000 habitantes. Los departamentos deberían ser suprimidos. Con estas medidas se reducirían considerablemente los gastos de la administración y se ganaría en eficacia.

El mismo día en que recibió el informe, Sarkozy mostró su rechazo a algunas de sus principales propuestas con estas palabras: "No creo que los franceses estén dispuestos a renunciar a la legitimidad histórica de los departamentos". El presidente de la Asamblea de los departamentos de Francia, el socialista Claudy Lebreton también manifestó su rechazo a una propuesta que calificó de iconoclasta e incongruente.

\section{b) El Comité Baladur (2009)}

Ese mismo año, mediante un decreto presidencial del 22 de octubre, el presidente Sarkozy creó un Comité - cuya presidencia atribuyó al antiguo primer ministro E. Baladur - para "estudiar las medidas adecuadas para simplificar las estructuras de las colectividades locales, clarificar el reparto de sus competencias y permitir una mejor asignación de sus recursos financieros, y formular toda otra recomendación que considere útil». El Comité entregó su informe al Presidente el 1 de marzo de 2009 (36).

El diagnóstico era muy parecido al efectuado por la Comisión Atali. La primera recomendación consistía en reducir el número de regiones de 22 a 15, para dotarlas de una población media de 3 a 4 millones de habitantes. El Comité no proponía suprimir los departamentos sino favorecer sus agrupamientos voluntarios y en todo caso, definir mejor sus facultades. Por otro lado, proponía también reforzar las intermunicipalidades y para

(35) Rapport de la Commission pour la libération de la croissance française sous la presidence de J. Attali, La documentation française, Paris, 2008. Sobre nuestro tema: proposiciones 260 y 261 , pág. 197.

(36) Comité para la reforma de las entidades locales presidido por E. Balladur, II est temps de décider, Rapport au Président de la Republique, Documentation Française, Fayard, 2009. 
ello defendía la creación de once grandes metrópolis para dar un impulso a las intermunicipalidades más pobladas.

\section{Las reformas territoriales de N. Sarkozy en 2010}

Los referidos informes condujeron al Presidente Sarkozy a poner en marcha una reforma -configurada como el III Acto de la descentralización que se tradujo en la Ley 2010-1563 de 16 de diciembre de reforma de las colectividades locales. La reforma afectó a los aspectos institucionales y materiales del principio de libre administración de las colectividades (37).

Esta ley no suprimió el escalón departamental, sino que creó dos nuevas estructuras. La primera el área metropolitana como nuevo tipo de intermunicipalidades o establecimiento público de cooperación intermunicipal para reagrupar municipios - contiguos territorialmente que -en conjunto- cuenten con más de 500.000 habitantes. La segunda es el polo metropolitano para reagrupar municipios que sumen al menos 300.000 habitantes (siendo uno de ellos de más de 150.000) y sin que se requiera contigüidad territorial. Las áreas metropolitanas y los polos metropolitanos podrán elaborar y gestionar sus planes de desarrollo económico, ecológico, educativo, social y cultural, con objeto de mejorar la competitividad y la cohesión. El milhojas no sólo no desaparece -a pesar de que se contempla como hipótesis la supresión de los departamentos, la ley preserva la existencia tanto de estos como de las regionessino que se sustituye por una "tarta de boda» (38).

En todo caso, la ley tuvo el mérito de ocuparse de la atribución de competencias con el objetivo de reorganizar y simplificar un sistema basado en la superposición de competencias en un mismo ámbito, y de llevar a cabo una disminución del tamaño y coste de las estructuras político administrativas mediante la creación de la figura de los consejeros territoriales.

\section{IV.1. La supresión de la cláusula de competencia general de los departamentos y regiones}

Desde el punto de vista material, la ley pretendía clarificar el reparto competencial y, a esos efectos, suprimía la cláusula de competencia ge-

(37) Esta ley es el resultado de un maratón legislativo que tuvo poco eco en una opinión pública francesa que estaba entonces centrada en la reforma de las pensiones que se aprobó casi al mismo tiempo.

(38) BLAIRON, K.: «Organización territorial en Francia...ob. cit. Pág. 351. 
neral de los departamentos y regiones a partir del 1 de enero de 2015. A partir de ese momento, los departamentos y regiones sólo podrán intervenir en aquellas materias cuya competencia les sea atribuida por la ley(39). Se incorpora así el principio de competencias exclusivas para esos dos tipos de colectividades locales. La cláusula de competencia general se mantiene para los municipios.

Ahora bien, la ley no elaboraba un listado de competencias en sentido estricto y como ha advertido la doctrina, preveía numerosas excepciones que no permitían afirmar que la cláusula de competencia general hubiera desaparecido totalmente (40). En algunas materias (turismo, cultura, deporte) se establece expresamente - aunque sea con carácter excepcional - la competencia compartida entre las diversas colectividades territoriales. Igualmente, se prevé la posibilidad de delegación de competencias entre dos colectividades, o entre uno de ellos y una institución de cooperación intermunicipal. Finalmente, la ley prevé que el Consejo general y el Consejo regional puedan asumir - mediante decisión especialmente motivada - cualquier asunto de interés departamental o regional cuya competencia no haya sido atribuida por ley a otra colectividad.

\section{IV.2. La creación de la figura de los consejeros territoriales}

La otra novedad más significativa de la ley en orden a nuestro tema consistió en la sustitución de los consejeros regionales (de las Regiones) y de los consejeros generales (de los Departamentos) por los consejeros territoriales. Es decir, sin refundir las colectividades territoriales afectadas - departamentos y regiones - los representantes de esas dos colectividades se fusionaban (41). La ley retrasaba la puesta en marcha de esta medida, y precisaba que no entraría en vigor hasta 2014. Nunca llegó a hacerlo porque fue derogada antes de que pudiera desplegar sus efectos. En todo caso, se trataba de una medida que contribuía a racionalizar las estructuras administrativas de las colectividades y a reducir sus costes por lo que consideramos oportuno exponer brevemente su alcance.

Recordemos, que hasta la reforma de 2010, departamentos y regiones disponían de órganos propios:

(39) Art. 73, párrafo IV, de la ley de 16 de diciembre de 2010. La supresión fue respaldada por el Consejo Constitucional. Decisión n. ${ }^{\circ}$ 2010-618, considerando 54.

(40) BLAIRON, K.: "La dimensión del Estado y de las Administraciones Públicas en perspectiva comparada: el caso francés» en Revista de Derecho Constitucional Europeo, núm. 21, 2014, pág. 118.

(41) «Dada esta fusión de representantes, se predijo que finalmente desaparecería una u otra colectividad (...) Este era probablemente uno de los mayores beneficios de esta ley". BLAIRON, K.: "La dimensión del Estado y de las Administraciones Públicas...ob. cit. Pág. 119. 
a) En los departamentos, la asamblea deliberante es el Consejo General. Se compone de los consejeros generales elegidos -en el marco de cada cantón del departamento- por un mandato de 6 años y renovados por mitades cada tres (42). Tras cada renovación parcial, el Consejo General designa a los miembros del Ejecutivo (que tienen que ser consejeros): el presidente y la Comisión permanente compuesta por un número que oscila de 4 a 10 vicepresidentes.

b) En las regiones, el órgano deliberante es el Consejo Regional cuyos escaños se reparten entre los departamentos según criterios de proporcionalidad en función del último censo general de población. Los consejeros regionales se eligen también por sufragio universal para un mandato de 6 años (43). El Consejo Regional elige de entre sus miembros a su Presidente, conocido como Presidente de la Región. Y a la Comisión Permanente, compuesta por un número que oscila entre 4 y 15 vicepresidentes.

La reforma de 2010 incluía la sustitución de los consejeros generales y regionales por un único tipo de consejeros: los consejeros territoriales. Estos ejercerían un solo mandato con dos representaciones distintas. Ocuparían su escaño, unas veces en la asamblea regional y otras en la asamblea departamental que ahora se denomina expresamente Consejo departamental.

La implantación de este tipo de consejeros únicos - en sustitución de los otros dos anteriormente existentes - obedecía a razones de orden presupuestario y de reducción de costes (44). Con la reforma, los 3471 consejeros territoriales reemplazarían a los 3963 consejeros generales y a los 1880 consejeros regionales existentes, es decir, a un total de 5.843 representantes. Se produciría, por tanto, una reducción en el número de consejeros de las colectividades mencionadas de 2372 cargos.

Una primera ley fue necesaria para hacer coincidir la renovación de los consejeros generales y los regionales (45). Los consejeros regionales

(42) El voto es uninominal, mayoritario y a doble vuelta. Para poder presentarse a la segunda vuelta, debe alcanzarse un umbral mínimo del 10 por ciento de los votos. Desde la Ley 2008-175, de 26 de febrero, se aplica el principio de paridad para garantizar el acceso igual de hombres y mujeres al Consejo General.

(43) El voto es por listas, con escrutinio proporcional a doble vuelta. Existe una prima a la lista vencedora con límite en un cuarto de los escaños. Para presentarse a la segunda vuelta, las listas deben superar el 10 por ciento de los votos.

(44) En todo caso, estos datos deben completarse con otros como los gastos y retribuciones suplementarias de los nuevos consejeros territoriales, y en concepto de dietas de viaje y remunueraciones de los suplentes: FAURE, B.: "Le regroupement départements-région. Remède ou problème" AJDA, 2011, pág. 86; PHILIP-GAY, M.: "Le conseiller territorial» en AJ Collectivités territoriales, 2011, pág. 54.

(45) Ley 2010-145, de 16 de febrero. 
electos en marzo de 2010 y los consejeros generales en parte renovados en 2011, verían reducido su mandato a 4 años los primeros, y tres los segundos. Ello permitiría elegir en marzo de 2014 a los nuevos consejeros territoriales para un mandato de 6 años.

La cuestión más controvertida fue el modo de elección de los consejeros (46). Al ser cargos electos que van a representar a dos tipos de colectividades, se propuso en un principio el sistema de voto mixto: la mayor parte de los representantes $(80 \%)$ procederían del escrutinio mayoritario uninominal a una sola vuelta en el marco del cantón; el 20 $\%$ restante serían elegidos a través de listas departamentales mediante escrutinio proporcional. Sin embargo, se impuso finalmente el sistema de votación previsto para los consejeros regionales: voto uninominal mayoritario a dos vueltas en el marco de los cantones. Para pasar a la segunda vuelta se requiere e $12.5 \%$ de los votos. En defensa de este sistema se alegó que favorece el bipartidismo, pero no faltaron tampoco las críticas. Las primeras, las relativas a la cuestión de la paridad. En su recurso ante el Consejo Constitucional, los demandantes denunciaban el desconocimiento de la paridad, en la medida en que el sistema electoral establecido suponía un retroceso muy importante de la representación de las mujeres en los consejos regionales en relación al sistema de voto vigente hasta entonces (47). Junto a ellas, otras críticas denunciaban que el sistema electoral beneficiaba la representatividad de los departamentos en detrimento de la de las regiones. Se criticaba la «infiltración de la región por la democracia departamental y su pérdida de sustancia democrática propia: aquella cuenta ciertamente con un consejo electo, pero por otra colectividad, dejando de aparecer como una colectividad primaria»(48). El Consejo desestimó también estas alegaciones (49) y se limitó a anular las disposiciones de la ley relativas a la

(46) De hecho, fue recurrido, con éxito, ante el Consejo Constitucional. En todo caso, en el corazón de esta reforma «se encuentra la traducción orgánica del principio de autogobierno de las entidades territoriales". BLAIRON, K.: "La dimensión del Estado y de las Administraciones Públicas...ob. cit. Pág. 119.

(47) Consejo Constitucional, decisión n. ${ }^{\circ}$ 2010-618 DC del 9 de diciembre de 2010, considerando 33. Los demandantes veían en ello una violación del párrafo segundo del artículo 1 de la Constitución según el cual «la ley favorece el igual acceso de las mujeres y los hombres a los mandatos electorales y cargos electos, así como a las responsabilidades profesionales y sociales". Ley Constitucional 2008-724 de 23 de julio. El Consejo no censuró el nuevo sistema electoral, considerando que la citada disposición constitucional no impide que el legislador sea libre para fijar el régimen electoral de las asambleas locales (art. 34. 7 Constitución). Esa disposición constituye solo una habilitación atribuida al legislador para favorecer la paridad mediante normas que - sin esa habilitación - serían contrarias al principio de igualdad tal y como es interpretado por el Consejo. Considerando 34 de la Decisión citada.

(48) FAURE, B.: Droit des colectivités territoriales, Dalloz, Paris, 2009.

(49) MARCOU, G.: "Le Conseil constitutionnel et la réforme des collectivités territoriales» en Actualité juridique du Droit Administratif, 2011, pág. 129. 
determinación del número de consejeros en función de la población subrayando que la igualdad demográfica debe prevalecer sobre cualquier otro tipo de consideraciones (50).

Estas reformas no llegaron a entrar en vigor. La victoria socialista en las presidenciales y legislativas de 2012 determinó que fueran derogadas antes de desplegar sus efectos. La cláusula de competencia general fue inicialmente restablecida en 2014 - para ser de nuevo suprimida un año después - y la figura de los consejeros territoriales eliminada.

Ley orgánica $n .^{\circ} 2013-403$ de 17 de mayo, relativa a la elección de los consejeros departamentales, municipales y de las agrupaciones de municipios suprimió la figura de los consejeros territoriales e introdujo importantes modificaciones en el procedimiento de elección de los consejeros generales que pasaron a denominarse consejeros departamentales (51). De la misma forma, los Consejos generales se convirtieron en Consejos departamentales. A partir de ahora, el mandato de los consejeros departamentales es de 6 años, suprimiéndose el sistema de renovación parcial por mitades cada tres años hasta entonces vigente. La elección se verifica mediante el escrutinio binominal, mayoritario a dos vueltas (52). En cada uno de los 2054 cantones es elegida una candidatura binominal siempre compuesto de un hombre y de una mujer. Además, estas circunscripciones cantonales que prácticamente no habían experimentado cambios desde su creación en 1790 han sido objeto de una profunda revisión de sus límites y se han reducido a la mi$\operatorname{tad}(53)$.

(50) Considerando 38 de la Decisión citada.

(51) VERPEAUX, M.: "La réforme des modes de scrutin locaux: révolutions et continuités» en Juris-Classeur péridique, édition Administration et collectivités territoriales, $\mathrm{n} .{ }^{\circ}$ 2186, 2013; POTIER, F: "L'architecte, la parité et le métronome: retour sur l'edification des nouvelles règles électorales pour les élections locales" en Juris-Classeur périodique, édition Administration et collectivités territoriales, n. ${ }^{\circ} 2187,2013$.

(52) Para conseguir la victoria en la primera vuelta, una candidatura binominal debe conseguir más del 50 por ciento de los votos y los sufragios de al menos el 25 por ciento de los electores inscritos. Si no se dan estas condiciones, las candidaturas que superen el 12, 5 por ciento de los votos de los electores inscritos pasan a la segunda vuelta.

(53) Hasta ahora existían 4035 cantones. La reducción del número de cantones a la mitad evita la duplicación de consejeros que habría provocado la introducción de las candidaturas binominales. La necesidad de fomentar la paridad se basaba en el dato de que las mujeres eran sólo el 13 por ciento de los consejeros departamentales - en el momento de aprobarse la ley-. El objetivo de las nuevas delimitaciones era corregir las deficiencias de la anterior demarcación para que la disparidad de la población de los diferentes cantones no supere en ningún caso el 20 por ciento. Generó gran controversia y la oposición acuso al Partido Socialista de diseñar el nuevo mapa cantonal pensando en sus propios intereses. La tramitación legislativa del proyecrto entre enero y abril de 2013 resultó muy controveretida. En la lectura definitiva del proyecto en la Asamblea Nacional, el texto se aprobó con 273 votos a favor y 247 votos en contra. 
Las competencias de los nuevos consejeros departamentales son limitadas, y como veremos, se circunscriben al ámbito de la solidaridad: protección de la infancia y distribución de ciertas ayudas sociales, equipamientos escolares y de bibliotecas, y gestión de determinadas carreteras.

Las primeras elecciones departamentales - ya no se denominan cantonales - con arreglo a la nueva normativa se celebraron los días 22 y 29 de marzo de 2015, es decir antes de que su ámbito competencial definitivo fuera fijado, tarea que corresponderá - como veremos en el epígrafe octavo - a la ley de 7 de agosto de 2015.

En todo caso, dentro del proyecto reformista de F. Hollande, e implementado por su primer Ministro, Manuel Valls, figura en el horizonte de 2020 la supresión de los departamentos, por lo que las de marzo de 2015 podrían haber sido las últimas elecciones departamentales. Todo ello en el supuesto de que de las elecciones de 2017 surja una mayoría comprometida con esta reforma pendiente de la arquitectura territorial francesa.

\section{Las reformas territoriales de F. Hollande}

En el contexto que acabamos de describir, el presidente F. Hollande era plenamente consciente de la necesidad de las reformas, y por ello encargó al gobierno una ambiciosa y profunda reforma - global- de la arquitectura territorial de la República para simplificar el milhojas administrativo, evitar duplicidades, reducir costes aprovechando economías de escala, y todo ello fortaleciendo a las regiones en detrimento de los departamentos. Esto suponía llevar a cabo la profunda $-\mathrm{y}$ controvertidareconfiguración del mapa regional demandada por los autorizados informes anteriormente expuestos, y que ningún gobierno hasta la fecha se había atrevido a implementar.

En cumplimiento de un encargo presidencial expreso, el 18 de junio de 2014, el Consejo de Ministros aprobó dos proyectos de ley -complementarios - cuya finalidad común era llevar a cabo una profunda reforma del sistema de descentralización territorial de la República:

a) El primero de ellos era el "Projet de loi portant nouvelle organisation territoriale de la République» (54). Este proyecto pretendía reforzar las regiones transfiriéndoles muchas de las competencias que hasta el momento ejercían los departamentos. El propó-

(54) Presentado por la Ministra de la función pública y de la descentralización, Mme Marylise Lebranchu, y por el Secretario de Estado para la reforma territorial, M. André Vallini. 
sito último era suprimir los departamentos en el Horizonte 2020. El proyecto se convirtió en ley promulgada el 7 de agosto de 2015.

b) El segundo, el «Projet de loi relatif à la délimitation des régions, aux élections regionales et departamentales et modifiant le calendrier électoral» (55). Este proyecto llevaba a cabo una profunda modificación del mapa regional, reduciendo el número de regiones para dotarlas de una "talla crítica» en cuanto a su población, territorio y recursos económicos. Se pretendía con ello mejorar la eficacia y la eficiencia de las políticas públicas. El proyecto - tras una agitada tramitación parlamentaria que examinaremos a continuación - se convirtió en la Ley núm. 2015-29 de 16 de enero de 2015.

En los epígrafes siguientes nos ocuparemos de ambos textos. Iniciamos la exposición con el segundo de ellos que fue el primero en ser aprobado y el que más controversia generó.

\section{La creación de regiones de talla europea: la ley 2015-29 de 16 de enero de 2015}

El objetivo fundamental que perseguía el «Projet de loi relatif à la délimitation des régions, aux élections regionales et departamentales et modifiant le calendrier electoral» era llevar a cabo una muy significativa reducción el número de regiones para dotarlas de una "talla crítica» en cuanto a su población, territorio y recursos económicos. Se pretendía con ello mejorar la eficacia y la eficiencia de las políticas públicas. El proyecto - tras una agitada tramitación parlamentaria que examinaremos a continuación - se convirtió en la Ley núm. 2015-29 de 16 de enero de 2015.

El proyecto pretendía optimizar recursos y racionalizar la gestión pública. El problema - como bien sabemos en España- es que el debate territorial no siempre se plantea en términos de pura racionalidad y eficacia administrativa. Las cuestiones identitarias contaminan frecuentemente el debate y así ha ocurrido en Francia. Sin embargo, como veremos, la racionalidad se ha impuesto a la "tradición» y, de esa forma, ha sido posible llevar a cabo una muy significativa simplificación del mapa regional de Francia que ha pasado de 22 regiones metropolitanas a 13 .

(55) Presentado por el Ministro del Interior, M. Bernard Cazeneuve. 


\section{VI.1. Estructura y contenido del proyecto de ley}

El proyecto estaba dividido en 4 capítulos y constaba de 12 artículos.

El primer capítulo era el que tenía por objeto llevar a cabo una nueva delimitación de las regiones metropolitanas (56), reduciendo su número que pasaba, de las 22 iniciales a las 13 actuales. La redefinición del mapa regional se efectúa respetando la integridad de las regiones existentes, esto es, sin desmembrar ninguna de ellas, de modo que algunas se mantienen y otras se fusionan (art. 1) (57). El nuevo mapa, según el art. 4 del proyecto, debía entrar en vigor el 1 de enero de 2016 (58).

El segundo capítulo - como consecuencia del anterior- lleva a cabo la correspondiente modificación del reparto de consejeros regionales. Se modifica el número de consejeros como consecuencia de la modificación del número de regiones y de la necesaria actualización de los censos (art. 6). Los consejeros siguen siendo elegidos en la región sobre una base departamental, y se asegura que todos los departamentos de una región tengan un representante en el consejo regional (art. 7).

Los capítulos tercero y cuarto - de menor interés para nuestro trabajo- se refieren a la posibilidad de celebrar elecciones parciales a los consejos regionales (59) y al calendario electoral, en general (60).

\section{VI.2. La finalidad del proyecto: la creación de regiones de «talla europea»}

El relator del proyecto de ley para la Comisión Especial del Senado encargada de examinarlo en primera instancia subrayó que su finalidad

(56) La regulación no afectaba a los territorios de Ultramar. La colectividad territorial de Córcega -que no es una región pero ejerce sus competencias - tampoco se ve afectada por este proyecto. En todo caso, a partir del 1 de enero de 2018, la colectividad de Córcega se convertirá en una colectividad de estatuto particular (que sustituirá a la colectividad territorial de Córcega y de los Departamentos de Corse du Sud et de Haute-Corse).

(57) Seis regiones no ven afectado su territorio por el proyecto. Se trata de las regiones de Aquitaine, Bretagne, Ile-de-France, Nord-Pas-de-Calais, Pays-de-la-Loire, Provence-Alpes-Côte-D'azur.

(58) Por decreto, antes del 31 de diciembre de 2015, se fijarían, provisionalmente, las capitales de las nuevas regiones, $y$ antes del 1 de julio de 2016, definitivamente.

(59) Esta posibilidad se introdujo como consecuencia de la decisión del Consejo Constitucional sobre el artículo 15 de la ley de 17 de mayo de 2013 relativa a la elección de consejeros departamentales y municipales, que declaró inconstitucional el sistema de dejar vacantes hasta las siguientes elecciones generales en el departamento las bajas sobrevenidas durante el mandato. Este sistema de elecciones parciales entró en vigor en diciembre de 2015.

(60) El proyecto establecía que - como consecuencia de la redefinición del mapa regional- las siguientes elecciones regionales se trasladan de marzo de 2015 a diciembre del mismo año. 
esencial no era tanto aprovechar las economías de escala(61), como construir unas nuevas regiones de "talla europea». El objetivo asignado a la reforma - subrayó el relator - es «doter les régions françaises d'une taille critique qui leur permette d'exercer à la bonne échelle les compétences stratégiques qui leur sont attribuées, de rivaliser avec les collectivités comparables en Europe et de réaliser des gains d'efficience» (62). Y a esos efectos, realizó una serie de estudios comparativos con las entidades equivalentes de Alemania, Italia y España. Efectivamente, la creación de grandes regiones capaces de competir eficazmente con las comunidades comparables en otros Estados europeos es una de las finalidades esenciales de esta ley(63). Las fusiones propuestas por el Gobierno permitirían situar a las regiones francesas en lo alto de la clasificación en términos de población y superficie y aproximar su peso económico al de las regiones alemanas (64).

Pero junto a esa finalidad, el estudio de impacto del proyecto de ley también mencionaba expresamente como finalidad del mismo, ganar eficiencia. Se trata de realizar economías de escala, a través de la fusión de las regiones existentes, y ello al margen de las competencias que le puedan ser transferidas.

De hecho, el Secretario de Estado para la reforma territorial, A. Vallini, señaló que con la reforma proyectada por el Gobierno se produciría un ahorro estimado entre 12.500 y 25.000 millones de euros, sobre la base de una reducción del 5 al $10 \%$ de los gastos totales de las colectividades territoriales. Ahora bien, esta estimación se refiere al conjunto de la reforma territorial. El nuevo mapa regional por sí sólo no liberará tantos recursos. Realmente será la otra ley - complementaria de esta - la que al transferir competencias de los departamentos a las nuevas regiones facilitará la creación de economías de escala y la reducción de costes.

(61) En todo caso, el análisis de impacto del proyecto de ley sí que aludía expresamente a la reducción de costes económicos - en términos de gastos generales de administración y personal- que supondría el nuevo mapa. Se aludía a modo de ejemplo a las reformas llevadas a cabo en Suecia y Polonia.

(62) «Dotar a las regiones francesas de una talla crítica que les permita ejercer, a buena escala, las competencias estratégicas que se les atribuyen, competir con las comunidades comparables en Europa y mejorar la eficacia.»

(63) Las regiones francesas son menos densas (98 habitantes por kilómetro cuadrado en Francia, contra 100 en España, 171 en Italia y 215 en Alemania) y tienen un peso económico inferior al de sus homólogas europeas. Las regiones francesas tienen un PIB muy por debajo del de las de Alemania. Son las menos potentes económicamente de los cuatro países comparados (Alemania, Italia y España). Así la parte de cada región francesa en el PIB es del 2,8 \% de media, cuando esa parte representa el 3,6 \% en los otros tres países.

(64) Lo que ya había sugerido el Comité para la Reforma de las colectividades territoriales, presidido por Balladur, en marzo de 2009: «El alcance de algunas de las regiones francesas se revisará, de manera que, sin subestimar la fuerza de ciertas identidades regionales vinculadas a los territorios de igual importancia, la división de las regiones les permitirá ocupar una mejor posición en la clasificación entre todas las regiones europeas». 


\section{VI.3. Una tramitación parlamentaria muy conflictiva}

La tramitación parlamentaria resultó - como veremos - muy complicada. La delimitación del nuevo mapa regional fue -como era previsible- muy controvertida. La posibilidad de introducir modificaciones en este mapa, a través de acuerdos de fusión o segregación voluntarios, resultó también una cuestión muy conflictiva.

Las posiciones del Senado y de la Asamblea sobre este último asunto estaban muy enfrentadas. El ordenamiento preveía ya la posibilidad de llevar a cabo esas modificaciones, pero establecía un procedimiento tan complejo y costoso que nunca se puso en marcha. El Senado quería modificarlo, para flexibilizarlo y facilitar su utilización garantizando así «un derecho de opción" de las regiones en el ámbito de su propia configuración. La Asamblea Nacional, por su parte, percibía esos intentos de flexibilización más que como un supuesto "derecho de opción" como una amenaza y riesgo ciertos de «inestabilidad territorial». La controversia se extendía a la procedencia - o no - en esos casos de apelar directamente al electorado en referéndum para ratificar esas modificaciones (65). Como acertadamente ha advertido Boto Alvarez en su clarificadora crónica sobre la ley que nos ocupa «tildar la tramitación (parlamentaria) de tumultuosa no es una mera licencia estilística» (66).

El Gobierno y el Senado se enfrentaron abiertamente en la tramitación del proyecto. El mismo día de su aprobación por el Consejo de Ministros (18 de junio de 2014), fue presentado ante el Senado para que fuera tramitado por el procedimiento acelerado. La Conferencia de Presidentes del Senado se opuso a esta pretensión (67) y lo envió para su examen a una Comisión especial.

El 26 de junio, la Conferencia de Presidentes del Senado acordó el rechazo del examen del proyecto por carecer este del estudio de impacto suficiente. El Primer Ministro - que sostenía que el proyecto sí estaba acompañado del estudio de impacto y que este era suficiente- presentó un recurso ante el Consejo Constitucional, activando así por vez primera el apartado cuarto del artículo 39 de la Constitución(68). El Consejo Constitucional en su Decisión 2014-12 de 1 de julio de 2014 declaró que el proyecto de ley reunía todos los requisitos exigidos por la Ley orgánica

(65) HOURQUEBIE, F:: "La nouvelle carte des regions: question de bon sens ou de baronnie?" en Actualité Juridique. Droit Administratif, núm. 11, 2015.

(66) BOTO ÁLVAREZ, A.: "Una nueva perspectiva para la optimización administrativa: la reorganización regional en Francia» en Revista General de Derecho Administrativo, núm. 39, 2015.

(67) Al amparo de lo previsto en el artículo 29. 6 del Reglamento del Senado.

(68) COMBRADE, B.L.: "Cinq ans plus tard: première (et dernière) application de l'article 39, alineá 4 de la Constitution» en Les Petites Affiches, núm. 171, 2014. 
núm. 2009-403 de 5 de abril de 2009 relativa a la aplicación de los artículos 34.1, 39 y 44 de la Constitución, permitiendo así la continuidad del procedimiento legislativo. Ese mismo 1 de julio, treinta senadores presentaron una moción para que el proyecto de ley fuera sometido a referéndum (69). Al día siguiente, la Comisión de Leyes constitucionales de la Asamblea Nacional rechazó la moción por tratarse de una maniobra dilatoria. La Asamblea criticaba el hecho paradójico de que siendo el Senado una Cámara representativa de las colectividades territoriales renunciara a ejercer sus funciones constitucionales en este ámbito (70).

Fracasados todos sus intentos por impedir la tramitación del proyecto, el Senado se vio obligado a examinarlo y aprobó en primera lectura un texto en el que todas las referencias a la redefinición del mapa regional habían desaparecido. Este fue el comienzo de un intercambio de versiones sucesivas - primera y segunda lecturas en la Asamblea y en el Senado- del proyecto con diferentes mapas regionales que concluyó sin acuerdo (71). La Comisión Mixta Paritaria (Asamblea-Senado) fracasó y ante la imposibilidad de alumbrar un texto consensuado por ambas cámaras, la Asamblea Nacional - en el ejercicio de sus competencias legislativas - aprobó el texto definitivo del proyecto el 17 de diciembre de 2014, que fue examinado después por el Consejo Constitucional.

\section{VI.4. El texto definitivo de la Ley 2015-29 de 16 de enero}

El texto finalmente aprobado está dividido en 5 capítulos y consta de 11 artículos.

Por lo que a nosotros interesa, el capítulo primero es el que lleva a cabo la reconfiguración del mapa regional.

El artículo primero enumera las 12 nuevas regiones (además de Córcega y las de Ultramar). Siete de las nuevas 12 regiones metropolitanas resultan de la fusión de dos o tres de las antiguas. Suceden a las fusionadas en derechos y obligaciones. El artículo segundo establece las reglas para la fijación de las capitales regionales. Y el artículo tercero regula los procedimientos de agrupación voluntaria entre regiones y de cambio de adscripción de departamentos a regiones limítrofes, lo que requiere en todo caso la aprobación por mayoría cualificada de tres quintos en sendas votaciones de los consejos territoriales afectados.

(69) http://www.senat.fr/leg/ppr13-666.html.

(70) http://assemblee-nationale.fr/14/rapports/r2098.asp.

(71) En su mayor acercamiento a las tesis de la Asamblea Nacional, el Senado llegó a defender un mapa con 15 regiones frente a las 13 propuestas. La ubicación de Languedoc y Midi dio lugar a fuertes debates. El Senado defendió siempre el mantenimiento de Alsacia como unidad. 
El capítulo segundo relativo a las elecciones regionales equipara la metrópolis de Lyon a un departamento (art. 4), actualiza el número de candidatos correspondiente a cada departamento (art. 5) y las reglas para garantizar la representación mínima de un representante por cada departamento de más de 100.000 habitantes en todos los consejos regionales (art. 6). Se introduce también la posibilidad de celebrar elecciones parciales tal y como se preveía en el proyecto de ley. Los siguientes capítulos se regulan las elecciones parciales y el calendario electoral.

\section{VI.5. La Decisión del Consejo Constitucional de 15 de enero de 2015}

Sesenta diputados y sesenta senadores interpusieron un recurso de inconstitucionalidad cuestionando tanto la concreta validez de 3 de los 11 artículos de la ley como el procedimiento parlamentario seguido para su aprobación. Los recurrentes alegaron también la vulneración de la Carta Europea de la autonomía local.

Diputados y senadores sostenían que el artículo 1 de la ley al establecer la fusión obligatoria de regiones - sin consulta previa a los territorios - era inconstitucional por lesionar el principio de libre administración de las colectividades territoriales. También consideraban inconstitucional el artículo 6 por lesionar la igualdad en el derecho de sufragio al no tener en cuenta a los departamentos menos poblados.

La Decisión núm. 2014-709 de 15 de enero de 2015 resolvió el recurso. El Consejo Constitucional, por un lado, se consideró incompetente para juzgar de presuntas vulneraciones de la Carta Europea de autonomía local y, por otro, recordó que ni la Constitución ni ninguna otra norma francesa exigen la consulta previa a los territorios para la modificación legislativa de su delimitación territorial. Desestimó también la queja de que la previsión de tratos diferenciados en función de la población de los departamentos vulnerase el principio de igualdad. Finalmente, y esta fue la única inconstitucionalidad apreciada, el Consejo Constitucional consideró contrario a la Constitución un párrafo del artículo 10 de la ley relativo a la financiación electoral.

Tras su controvertida tramitación la ley entró en vigor el 1 de enero de 2016. Se trata de la primera fase de un proceso que incluye también el proyecto de ley de competencias regionales en virtud del cual se transfiere a las regiones muchas de las competencias que ejercen los departamentos con vistas a la futura desaparición de estos (72). Esto

(72) GERARD, P.: «Premier point sur la réforme de I'Etat territorial?» en Actualité Juridique. Droit Administratif, núm. 8, 2015. Págs. 434 y ss. 
afectará también - como ha advertido Boto - a la gestión de ciertos servicios desconcentrados: "y quizás sea aquí donde radiquen los verdaderos ahorros y economías de escala: amortización de direcciones generales en agricultura, asuntos generales o juventud y deporte; fusión de agencias regionales de salud, inspecciones de educación, etc.» (73). Esta segunda ley complementaria de la anterior fue aprobada siete meses después.

\section{VI.6. Las elecciones regionales del 6 y 13 de diciembre de 2015}

Los días 6 y 13 de diciembre de 2015 se celebraron las primeras elecciones con el nuevo mapa regional. La elección de los Consejos regionales se lleva a cabo mediante un sistema de listas con escrutinio proporcional. El $75 \%$ de los escaños se distribuye mediante representación proporcional entre todas las formaciones políticas que hayan obtenido al menos un $5 \%$ de los votos. El restante $25 \%$ de los escaños es adjudicado como bonificación a la primera fuerza política.

\section{VI.7. Los Decretos del 28 de septiembre de 2016}

De conformidad con lo previsto en el artículo 2 de la ley, los decretos 1262 a 1269 de 28 de septiembre, publicados en el Journal officiel del 29 establecieron los nombres definitivos y las capitalidades de las siete nuevas regiones surgidas por fusión de dos o tres de las anterio$\operatorname{res}(74)$ :

- Le Grand Est comprende las antiguas regiones de Alsace, Champagne-Ardenne et Lorraine, con Strasbourg como capital.

- La Nouvelle-Aquitaine comprende las antiguas regiones de Aquitaine, Limousin et Poitou-Charentes, con Bordeaux como capital.

- L'Occitanie comprende las antiguas regiones de Languedoc-RoussiIlon et Midi-Pyrénées, con Touloose como capital.

- Les Hauts-de-France comprende las antiguas regiones de Nord-Pasde-Calais y Picardie, con Lille como capital.

(73) BOTO ÁLVAREZ, A.: "Una nueva perspectiva...ob. cit. Para preparar estas modificaciones el Gobierno mediante la Circular núm. 5770-SG de 18 de febrero de 2015 relativa a la reorganización de los servicios regionales del Estado, encargó a los prefectos realizar un diagnóstico de la situación producida tras la reconfiguración del mapa regional para mejorar el funcionamiento de la administración territorial del Estado.

(74) Cuatro regiones, conservan su antigua delimitación, su nombre y su prefectura (capitalidad) Bretagne, île-de-France, Provence-Alpes-Côte d'azur et Pays-de-la-Loire. La région Centre-Val de Loire solo modifica su nombre (antiguamente Centre). 
- La Normandie comprende las antiguas regiones de la Haute y de la Basse-Normandie, con Rouen como capital.

- L'Auvergne-Rhône-Alpes adopta definitivamente su nombre provisional, con Lyon como capital.

- La Bourgogne-Franche-Comté, adopta también definitivamente su nombre provisional con Dijon como capital.

El nuevo mapa regional de Francia con sus capitales regionales quedaba así definitivamente establecido.

\section{La transferencia de competencias departamentales a las regiones: la ley de 7 de agosto de 2015}

A diferencia de lo ocurrido con el anterior proyecto de ley -que enfrentó duramente a la Asamblea Nacional y al Senado y ante la falta de acuerdo entre ambas cámaras hubo que recurrir al procedimiento que otorga a la Asamblea la última palabra para la aprobación de la ley- en este caso, la Comisión paritaria mixta alcanzó un acuerdo que permitió que el texto final de la ley fuese aprobado por la Asamblea Nacional y el Senado 16 de julio de 2015 (75).

EI 22 de julio, sesenta diputados y sesenta senadores interpusieron un recurso ante el Consejo Constitucional que en su Decisión de 6 de agosto declaró inconstitucional la disposición relativa al modo de elección de los consejeros metropolitanos del Gran París.

El objetivo de esta ley - complementaria de la anterior- es clarificar el confuso sistema de reparto competencial entre las distintas colectividades territoriales y potenciar las competencias de las regiones. Para ello, la ley sobre la nueva organización territorial de la República, por un lado, suprime la cláusula de competencia general para los departamentos y regiones $y$, por otro, asigna nuevas competencias a las regiones en detrimento de los departamentos.

\section{VII.1. La eliminación de la cláusula de competencia general}

Las leyes de descentralización de 1982 y 1983, así como la ley sobre responsabilidades locales de 13 de agosto de 2004, atribuyeron a las colectividades locales competencias propias. La sucesión de textos legislati-

(75) El proyecto de ley había sido aprobado en primera lectura, con modificaciones, por el Senado el 27 de enero de 2015, y en primera lectura, con modificaciones, por la Asamblea Nacional el 10 de marzo de 2015. El procedimiento acelerado se había iniciado el 5 de diciembre de 2014. 
vos condujo a un entrecruzamiento de las competencias y a un alejamiento progresivo del diseño inicial del reparto. Ese diseño se basaba en una triple clasificación: las competencias sobre las materias de proximidad debían corresponder a los ayuntamientos, las relativas a materias sociales a los departamentos y las relacionadas con el desarrollo económico y la ordenación del territorio a las regiones (76).

Ahora bien, sobre estas últimas materias - de competencia regionaly de contornos muy amplios, el resto de colectividades territoriales también puede intervenir (77) . Y puede hacerlo en virtud de la denominada cláusula de competencia general (78). La cláusula de competencia general implica que una colectividad territorial puede intervenir en un ámbito cuya competencia está atribuida a otra, apelando al interés territorial de la materia.

Para evitar esta concurrencia la ley suprime la cláusula de competencia general de los departamentos y regiones (79). Ninguna de estas colectividades podrá intervenir ya sobre la totalidad de los asuntos públicos. Con ello se pretende clarificar "que fíat quío" (quién hace qué), armonizar las políticas públicas, y evitar los gastos inútiles que genera la concurrencia de diferentes colectividades sobre un mismo asunto (80).

La cláusula de competencia general se mantiene para los ayuntamientos (81) cuyas competencias expresas comprenden la movilidad y la calidad del aire.

(76) PONTIER, J. M.: «Trente ans de répartition et de resdistribution des compétences entre l'Etat et les collectivités territoriales» en Bulletin juridique des collectivités locals, 2012. 275.

(77) A fecha de 2010, la intervención de los departamentos en esas materias suponía el 20 por ciento de sus gastos (11.000 millones de euros).

(78) La ley de 16 de diciembre de 2010 suprimió la claúsula de competencia general de departamentos y regiones con carácter general, aunque estableció algunas excepciones. El Consejo Constitucional declaró la constitucionalidad de la norma en su Decisión de 9 de diciembre de 2010. Pero fue restablecida nuevamente en 2014 por la ley de modernización de la acción pública territorial. Y ahora ha sido nuevamente suprimida. La doctrina ha criticado con razón estas vacilaciones: "Con vacilaciones tan evidentes y toscas se entiende la sensación de falta de sentido de estos intentos de reescribir la organización territorial francesa». ALCARAZ, H.: "La organización territorial francesa en 2015: ¿Hacia una redefinición territorial?» en Cuadernos Gimenez Abad, núm. 10, 2015, pág. 33.

(79) Esa competencia general era una de las notas distintivas en el Derecho francés de las colectividades territoriales, y la que las diferenciaba de los establecimientos públicos. Con la reforma de 2015, el régimen jurídico de las colectividades se fragmenta en dos grupos según dispongan o no de la mencionada cláusula.

(80) PONTIER, J. M.: "La redefinition des competences: à la recherche de la cohérence» en Revue du Droit Public, 2015. 1241.

(81) Se mantiene también para la metrópolis de Lyon y para Córcega, dotada de un estatuto particular. 


\section{VII.2. El reforzamiento del poder de las regiones en detrimento de los departamentos}

La ley refuerza el poder de las regiones mediante la transferencia a las mismas de competencias antes atribuidas a los departamentos (82), con la atribución de nuevas competencias, y a través de una extensión de su poder reglamentario.

Las competencias transferidas a las regiones del ámbito departamental son las siguientes:
a) Carreteras (83).
b) Colegios (enseñanza secundaria) (84).
c) Transportes interurbanos y escolares.
d) Puertos.

Además, la ley refuerza el papel de la región en términos de desarrollo económico (85). Ella será responsable de la política de apoyo a las pequeñas y medianas empresas. También será responsable del desarrollo sostenible y ejercerá competencias sobre ordenación del territorio, movilidad, lucha contra la contaminación del aire, recuperación de energía, vivienda y gestión de residuos (86).

La ley concentra en el ámbito departamental las competencias relativas a la solidaridad. Los departamentos pueden implementar cualquier ayuda o acción relacionada con la prevención o el tratamiento de las situaciones de fragilidad, cuidado de niños y situaciones de dependencia, etc. También son competentes para facilitar el acceso a derechos y servicios públicos a su cargo (87). Pueden también proporcionar asistencia fi-

(82) LONG, M.: «Le departement après la loi NOTRe, un acte de décès non transformé» en Actualité Juridique du Droit Administratif, 2015.

(83) Las carreteras departamentales transferidas a las regiones en el proyecto gubernamental siguen siendo competencia del departamento después de la primera lectura.

(84) En materia educativa, la gestión de los colegios se transfiere a las regiones mientras que la de las Universidasdes - después de la primera lectura del proyecto- sigue perteneciendo a los departamentos.

(85) En materia de desarrollo económico, la región es la colectividad encargada de elaborar el modelo regional de desarrollo económico, innovación e internacionalización, que es vinculante y define el régimen de las ayudas a las empresas (SRDEEI). Los departamentos ya no pueden intervenir tampoco en este ámbito salvo en aquellos casos expresamente previstos en la leyDenominado SRDEII (schéma régional de développement économique, d'innovation et d'internationalisation) fija las grandes orientaciones estratégicas de una región en materia económica. Previsto en la loi n. ${ }^{\circ} 2004-$ 809 du 13 août 2004 relative aux libertés et responsabilités locales.

(86) En el ámbito de la planificación y el desarrollo sostenible, la región es igualmente la colectividad competente para elaborar el modelo regional de desarrollo, sostenibilidad e igualdad de los territorios (SRADDET) que es vinculante.

(87) FAURE, B.: Droit des collectivités...ob. cit. pág. 563. 
nanciera a los municipios e intermunicipalidades de su territorio, y financiar inversiones para satisfacer necesidades de la población rural, por razones de solidaridad territorial cuando la iniciativa privada no lo haga.

En materia de turismo, la ley atribuye la competencia tanto a la región como al departamento.

Tras esta exposición de las reformas legislativas operadas en 2015 en el ámbito de la región (y del departamento), vamos a dedicar un epígrafe al modo en que se ha abordado el otro problema recurrente de la administración local francesa: la fragmentación municipal.

\section{Las respuestas a la extrema fragmentación municipal}

En el ámbito municipal se han llevado a cabo dos tipos de medidas. En primer lugar, se ha previsto legalmente la creación de nuevos municipios mediante fusión de varios preexistentes; en segundo lugar, se han potenciado las numerosas modalidades de cooperación intermunicipal.

\section{VIII.1. La creación de «nuevos municipios»}

De los 37.000 municipios franceses, 30.000 tienen menos de 2000 habitantes. A diferencia de otros Estados que han afrontado situaciones similares mediante una reducción del número de municipios, en Francia "L'esprit de clocher» ha impedido hasta la fecha llevar a cabo cualquier tipo de reconfiguración del mapa municipal.

Las leyes de 16 de diciembre de 2010 y de 16 de marzo de 2015 se configuran como el último intento de reducir el número de municipios mediante fusiones que impliquen la creación de nuevos municipios. Se trata en todo caso de fusiones voluntarias en las que la voluntad de la colectividad afectada resulta esencial. Las leyes de 2010-2015 prevén tres supuestos de creación de nuevos municipios: a) por iniciativa de municipios contiguos; b) a petición de un establecimiento público de cooperación intermunicipal (EPCI) con el acuerdo por mayoría cualificada de los municipios afectados; o c) a solicitud del prefecto con el acuerdo por mayoría cualificada de los municipios afectados.

El escepticismo inicial de la doctrina sobre la aptitud de este expediente para modificar sustancialmente el mapa municipal de Francia se ha confirmado con el dato de que tan solo se han creado 317 nuevos municipios por fusión de 1090 municipios ya existentes(88). El número de

(88) FAURE, B.: Droit des colectivités...ob. cit. pág. 355. 
municipios se ha reducido así en 2016 a 35.885. Se trata, como puede comprobarse, de una reducción insignificante.

\section{VIII.2. Los establecimientos públicos de cooperación intermunicipal (EPCI)}

Ante el escaso éxito de la fórmula de creación de nuevos municipios por fusión de varios existentes, el legislador ha previsto una serie de fórmulas - de cooperación - que al mismo tiempo que garantizan la supervivencia del municipio como colectividad dan lugar a un nuevo sujeto: los establecimientos públicos de cooperación intermunicipal o intermunicipalidades.

Los EPCI son personas jurídicas de Derecho Público que comprenden varios municipios. Se conocen también como «intermunicipalidades». Son una especie dentro de un género más amplio: el de los establecimientos públicos territoriales que permiten agrupar municipios, departamentos o incluso regiones. Administran un territorio compuesto por el de varios municipios preexistentes, y cuentan con órganos y competencias propias. Se configuran como un nuevo nivel de la administración descentralizada intermedio entre el municipio y el departamento.

Las intermunicipalidades han sido el expediente que ha permitido hacer frente con éxito a "l'émiettement comunal». El fundamento de los $\mathrm{EPCl}$ se encuentra en el Código General de Colectividades Territoriales cuya quinta parte está dedicada a la cooperación local. El Código dispone que «las colectividades territoriales pueden asociarse para el ejercicio de sus competencias creando organismos públicos de cooperación» (89). Su creación compete al prefecto con el acuerdo de los municipios afectados. La Ley de 12 de julio de 1999 impuso la exigencia de contigüidad territorial de los municipios asociados. Los EPCl están dotados también de un órgano deliberante cuyos miembros son elegidos en el marco de las elecciones municipales por sufragio universal directo. Se denominan según el tipo de EPCl: comité sindical, consejo de la comunidad o consejo de la metrópoli (90). Junto al órgano deliberante, tienen un órgano ejecutivo: el Presidente que es elegido por el Consejo.

En este contexto, la Ley de 7 de agosto de 2015 previó el establecimiento de un nuevo mapa municipal en el que la mayor parte de los municipios formara parte de una intermunicipalidad (91). Para ello, enco-

(89) Art. L. 5111-1. FAURE, B.: Droit des collectivités...ob. cit. pág. 380.

(90) Las leyes de 16 de diciembre de 2010 y de 17 de mayo de 2013 establecen el procedimiento electoral que ha sido aplicado por vez primera en las elecciones de marzo de 2014. En la misma operación electoral se elige a los consejeros municipales y a los consejeros de los EPCI.

(91) LACHAUME, J. F:: «Des intercommunalités reforcées» en Actualité jurdique du Droit administratif, 2015. 1905. DEGOFFE, M.: "La loi NOTRe et I'intercommunalités» en Bulletrin juridique des collectivités locales, 2015. 578. 
mendó a los prefectos la tarea de reorganizar los EPCl para potenciar su tamaño: ninguno de ellos debería contar con menos de 15.000 habitantes. A esa fecha, la mitad de los EPCI tenía una población inferior a esa cifra. A esos efectos, la ley facilita la fusión de intermunicipalidades. Se trata en suma de crear EPCl de suficiente talla crítica para cumplir con eficacia sus funciones. Es decir, de aplicar la misma lógica que había presidido la reforma de las regiones, ya examinada.

Existen diversos tipos de intermunicipalidad:

a) Sindicatos de municipios: es la modalidad más antigua y su creación se remonta a la ley de 22 de marzo de 1890(92). Pueden ser de vocación simple si se limitan a la gestión de un único servicio público, o de vocación múltiple si comprenden la cuasi totalidad de las competencias municipales. Las últimas reformas pretenden reemplazar muchos de ellos por otras fórmulas de cooperación, pero a pesar de ello cabe prever que su número se mantenga en torno a los 10.000(93).

b) Comunidades de municipios: esta modalidad se creó por la ley de 6 de febrero de 1992. Se trata de agrupaciones que ponen el acento en su carácter estratégico más que en la gestión de competencias en común. Se les asigna un objetivo: el desarrollo local. En 2015, existen 1884(94).

c) Comunidades urbanas: Creadas por la ley de 31 de diciembre de 1966 para resolver los problemas de desarrollo de las grandes aglomeraciones urbanas: Inicialmente se establecieron cuatro: Burdeos, Lille, Lyon y Estrasburgo (95). La ley de 27 de enero de 2014 ha reducido de 450.000 a 250.000 el número mínimo de habitantes exigido para formar una comunidad urbana. Esta reducción se justifica por el hecho de que para las ciudades más pobladas se recurre ahora a una nueva fórmula: las metrópolis.

d) Comunidades de aglomeración: Creadas por la ley de 12 de julio de 1999, se establecieron 50 al año siguiente y son ya 226 en el 2016 (cuentan con una población de 20 millones de habitantes)(96). En

(92) MAURICE, R: Le syndicat de comunes, Masson, Paris, 1961.

(93) En 2012 había 15.688 y en 2014 había 13.402. FAURE, B.: Droit des collectivités...ob. cit. pág. 402.

(94) Su número ha crecido últimamente puesto que en 1999 sólo eran 1347. Los 1884 acxtualmente existentes comprenden una población de 25, 3 millones de habitantes.

(95) Después se crearon 12 más: Entre 1969 y 1973: Brest, Cherbourg, Dunkerke, Le Creusot-Montceau-les-Mines y Le Mans; Nancy, Arras y Alençpn en 1995; Marsella, Toluse, Niza y Nantes en 2000. Hoy tras la generalización del estatuto de metrópolis para las grandes aglomeraciones conservan la condición de comunidad urbana 9 de ellas: Brest, Cherbourg, Dunkerke, Le Creusot-Montceau-lesMines, Le Mans, Nancy, Arras, Alençon y Dijon.

(96) BRIAND, P.: "Quelques réflexions à propos de la loi du 12 juillet 1999 et la création des communautés d'aglomeration» en Revue générale du collectivités territoriales, 2000. Págs. 395 y ss. 
principio, la ley exige un mínimo de 50.000 habitantes para formar una comunidad de aglomeración. Estas comunidades asumen todas las competencias municipales necesarias para el desarrollo económico, la ordenación del territorio y el urbanismo.

A 1 de enero de 2016, el 99,9\% de los municipios y el $99.7 \%$ de la población francesa pertenece a una intermunicipalidad.

\section{VIII.3. Las metrópolis}

La ley de 27 de enero de 2014 de modernización de la acción pública territorial y de afirmación de las metrópolis consagra la figura de la metrópoli y, con ella, pretende resolver el problema de la administración de las grandes ciudades sobre las que se superponían todos los escalones de la organización territorial (municipal departamental y regional) dificultando una política común. "Ello contribuía a desarmar nuestros grandes polos regionales - advierte Faure - en un contexto de competencia económica con sus homólogos europeos y mundiales» (97).

La originalidad de la metrópoli radica en el hecho de que asume un cierto número de competencias departamentales y regionales (98). De esta forma, la doctrina subraya que podrían configurarse como «el lugar esencial donde elaborar la política administrativa de una región» (99). En todo caso, la metrópolis no se configura -como preconizaba el informe Balladur al que antes hicimos referencia - como una nueva categoría de colectividad territorial (100), sino como una fórmula inédita y al margen de la organización administrativa tradicional que viene a reemplazar a los municipios y a los departamentos dentro de los límites de su territorio.

La ley n. ${ }^{\circ} 2014-48$ de 27 de enero de 2014 ha creado de oficio 9 metrópolis: Burdeos, Lille, Grenoble, Nantes, Niza, Rennes, Rouen, Estrasburgo

(97) FAURE, B.: Droit des collectivités...ob. cit. pág. 417.El primer reconocimiento de la metrópoli se produjo en la ley de 16 de diciembre de 2010, pero fue la de 27 de enero de 2014 la que la consagró en su alcance actual.

(98) MOZOL, P.: «Les competences métropolitaines, une remise en question du rôle joué par les collectivités territoriales dans la conduite de l'action publique locale? En Juris-Classeur périodique, édition des collectivités territoriales, 2011.

(99) FAURE, B.: Droit des collectivités...ob. cit. pág. 417. DOUENCE, J.C.: "Les metropoles» en Revue Frncçaise de Droit Administratif, 2011. 258.

(100) La metrópolis de Lyon dotada de un régimen singular responde mejor al modelo preconizado por el Informe Balladur. Lyon sí que es una auténtica colectividad territorial (en el sentido del art. 72 de la Constitución) que comprende el territorio de los municipios qur la conforman y que se mantienen. La comunidad urbana y el departamento desaparecen. Este es el modelo que se pensó para las metropólis, pero solo Lyon lo desarrolló. Las demás metrópolis, como vamos a ver, son establecimientos públicos, pero no colectividades territoriales en sentido estricto. 
y Toulousse. Y ha previsto también la creación de otras a iniciativa de los municipios afectados, y por decreto, en toda aglomeración urbana de más de 400.000 habitantes, en lugar de los EPCl correspondientes (101).

Las metrópolis son administradas por un consejo metropolitano cuyos miembros son elegidos por sufragio universal y que designa a su presidente. Como todo establecimiento público, las metrópolis reciben competencias de atribución, pero estas revisten un alcance muy amplio al asumir simultáneamente competencias que en otros casos pertenecen a los distintos escalones territoriales (municipios, departamentos y regiones). La lista de competencias de las comunidades urbanas constituye su elenco competencial básico. Por otro lado, recibe un número limitado de competencias que ejercerá en lugar de los departamentos y regiones (transportes escolares, carreteras departamentales, promoción de actividades económicas en el exterior). A ello se añaden las competencias suplementarias transferidas por convenio por las otras colectividades.

Las leyes de 27 de enero de 2014 y de 7 de agosto de 2015 amplían aún más el ámbito competencial de las metrópolis. Estas reciben obligatoriamente de sus municipios las competencias económicas, de ordenación del territorio, vivienda, urbanismo y medio ambiente; y de las demás colectividades - por convenio - como es el caso del departamento, las competencias sobre ayudas sociales, alojamientos, colegios, turismo y carreteras; y de la región, las competencias sobre institutos de secundaria y desarrollo económico; y del Estado, las competencias sobre vivienda, infraestructuras y vida universitaria.

Todas sus competencias deben ser ejercidas al servicio de la misión que la ley atribuye a las metrópolis: perseguir un proyecto de ordenación y desarrollo económico, ecológico, educativo, cultural y social de su territorio para mejorar su competitividad y su cohesión.

Junto a estas metrópolis de derecho común, el legislador ha creado otras dos con determinadas singularidades Gran París (102) y Aix-Marseille-Provence (103) y una metrópolis que es una verdadera colectividad territorial (Lyon). El examen de estas figuras desborda ya los límites de este trabajo.

(101) Así se crearon las metrópolis de Brest y de Montpellier, y por decreto publicado en el Journal officiel el 22 de abril de 2016, la que hace el número 12: la metrópolis del Grand Nancy, (en funconamiento desde el 1 de julio de 2016).

(102) El 1 de enero de 2016 se creó la metrópolis del Grtan Paris. Compende 131 municipios y sustituye a los $\mathrm{EPCl}$ existentes en el territorio. Su población total supera los 7 millones de habitantes. Su régimen jurídico básico es el de las metrópolis de derecho común, pero con excepciones significativas. DAUCE, S.: "La métropole du Gran Paris à I'issue de la loi NOTRe» en Juris-Classeur périodique, édition des collectivités territoriales, 2015.

(103) El mismo 1 de enero fue creada la metrópolis de Aix-Marseille-Provence. Comprende 92 municipios y sustituye a la comunidad urbana de Marsella-Provenza y de otros tres EPCI. Su población asciende a 1, 8 millones de habitantes. 
En todo caso, con lo expuesto hasta ahora estamos en condiciones de formular una serie de conclusiones sobre las reformas de la arquitectura territorial francesa llevadas a cabo durante la presidencia de F. Hollande.

\section{Conclusiones: luces y sombras de las reformas territoriales en Francia}

a) El modelo territorial francés vigente hasta la implementación de las reformas examinadas en este artículo se caracterizaba por una superposición de instancias territoriales: los municipios heredados del Antiguo Régimen, los Departamentos creados por la Revolución, y las Regiones establecidas para implementar las políticas y programas de las entonces Comunidades Europeas y hoy Unión Europea. Como colectividades territoriales, todas estas instancias disponían de una competencia general que les permitía intervenir sobre todas las materias en las que estuviera en juego un interés territorial y, en virtud del principio de libre administración, estaban regidas por órganos elegidos por sufragio universal. Se trata de un modelo complejo y costoso que provoca muchas duplicidades. No resulta claro qué colectividad tiene que intervenir en cada caso $\mathrm{y}$, al final, en muchos ámbitos intervienen varias, incrementando los costes y reduciendo la eficacia de las políticas públicas. Por otro lado, la extremada fragmentación municipal hace imposible que la inmensa mayoría de los municipios pueda gestionar eficazmente los servicios públicos locales, y el reducido tamaño de las regiones impide a estas colectividades aprovechar las economías de escala y competir con sus homólogas europeas. En este contexto, tanto en sede política como en sede académica, desde comienzos de siglo se venía insistiendo en la necesidad de llevar a cabo una reforma profunda y ambiciosa de la arquitectura territorial de la República.

b) Las reformas de la arquitectura territorial francesa impulsadas por el Presidente François Hollande, e implementadas por el Primer Ministro Manuel Valls, se sitúan en la estela de las políticas de optimización de los recursos Ilevadas a cabo en diversos países de Europa desde el comienzo de la crisis económica. Su objetivo es racionalizar el mapa territorial evitando la excesiva fragmentación (regional y municipal) y configurando unidades territoriales que, tanto a escala regional como municipal, puedan favorecer la competitividad y la cohesión. En este sentido, es preciso subrayar que las reformas no solo pretendían una reducción de los costes de funcionamiento del sistema y la liberación de recursos económicos. Ante todo, su objetivo era la constitución de regiones fuertes, 
capaces de competir con éxito con sus homólogas europeas en el contexto de la Unión Europea y del mundo globalizado. Esto exigía reducir el número de regiones, pero también reforzar sus competencias. En el plano municipal, de lo que se trataba era de fomentar mecanismos de cooperación intermunicipal y potenciar las asociaciones de municipios, así como de dotar de un estatuto especial a las grandes ciudades (metrópolis).

c) Desde esa óptica, las reformas se enfrentan a un problema recurrente de la descentralización: la racionalización del número de entidades territoriales. Diversos informes y Comités habían puesto de manifiesto la necesidad de reorganizar los diversos niveles territoriales. Las reformas tuvieron que enfrentarse con los intereses de los cargos electos, políticos locales, y el peso de la tradición, que se oponían $-y$ continúan oponiéndose- a la reducción significativa del número de municipios y de regiones.

d) Por lo que se refiere al ámbito regional, la reforma logró prosperar con la aprobación de dos importantes leyes en 2015 -y merece una valoración general positiva - pero los obstáculos que tuvo que superar fueron muchos y la tramitación de la ley del nuevo mapa regional resultó muy controvertida. Las reformas de 2015 fortalecieron las regiones dotándolas de la talla crítica necesaria para competir con sus homólogas europeas. El fortalecimiento se produjo a través de dos vías: la primera, la reducción del número de regiones metropolitanas de 22 a 13 mediante la fusión de regiones anteriormente existentes; la segunda, la supresión de la cláusula de competencia general de departamentos y regiones, y la expresa atribución a estas últimas de competencias que anteriormente ejercían los departamentos.

e) Por lo que se refiere al ámbito municipal, la fragmentación se mantiene y Francia sigue siendo el país con mayor número de municipios del mundo. Las reformas han consistido en la potenciación de los establecimientos de cooperación intermunicipal en general y, singularmente, en la creación de las metrópolis que asumen competencias de los diversos escalones territoriales (municipio-departamento y región) y permiten fijar una política administrativa única.

f) El reforzamiento de las regiones y la potenciación de las intermunicipalidades debería conducir a la supresión de los departamentos. Supresión que supondría una notable y definitiva simplificación del milhojas territorial. Desde esta óptica, hay que subrayar que sigue pendiente uno de los objetivos últimos del proceso reformista: la supresión de los departamentos. Una instancia territorial situada entre el municipio/intermunicipalidades y la región, cuyo reducido tamaño le impide llevar a cabo con la debida eficacia políticas de 
desarrollo económico, pero que es demasiado grande para ocuparse de la gestión diaria de los servicios públicos. La mayoría de los analistas y expertos coinciden en la necesidad de prescindir del escalón departamental y acabar así con muchas de las duplicidades existentes. Desde un punto de vista económico, el gasto de funcionamiento de los departamentos asciende a más de $60 \mathrm{mil}$ millones de euros. La supresión de los departamentos deberá llevarse a cabo, en su caso, mediante la oportuna reforma constitucional (vía referéndum o por el Parlamento reunido en Congreso, en cuyo caso se requiere una mayoría de tres quintos de los votos). A la vista de los últimos referendos celebrados tanto en Francia como en otros países y de los bajos niveles de popularidad del Jefe del Estado, la convocatoria de un referéndum de reforma constitucional, supone asumir un alto riesgo político, y ello convierte a la reforma por esta vía en una operación altamente improbable. Por otro lado, la reforma vía aprobación parlamentaria plantea dificultades no menores. En Francia no existe el consenso político necesario para garantizar su éxito.

g) Por ello, y debido al mantenimiento de los departamentos, las reformas analizadas no acaban con las duplicidades. Las reformas potencian a las regiones - no solo por haberlas dotado de talla crítica - sino también por haber incrementado su ámbito competencial en detrimento de los departamentos. Las grandes orientaciones estratégicas y las principales misiones económicas son ahora decididas por las regiones. A los departamentos se encomiendan los programas de solidaridad y redistribución. Los municipios se ocupan de los servicios de proximidad. Con todo ello se produce una notable clarificación competencial, pero en determinadas materias y algunas de ellas de gran importancia (por ejemplo, las infraestructuras) siguen convergiendo las competencias de diferentes instancias. Las duplicidades distan mucho de haber desaparecido.

h) En cuanto al ámbito municipal, la metrópolis de Lyon debió ser el modelo de las demás. Es decir, de lo que se trataría es de convertir a las metrópolis en colectividades territoriales en pie de igualdad con las regiones (tal y como proponía el informe Balladur). En todo caso, y a pesar de la compleja tipología de establecimientos de cooperación intermunicipal, la potenciación de las intermunicipalidades merece también una valoración positiva como fórmula alternativa a la fusión de municipios.

i) Finalmente hay que subrayar que todas las reformas analizadas en este trabajo, aunque necesarias y merecedoras de una valoración positiva, solo contaron con el respaldo de uno de los grandes 
partidos franceses. En diciembre de 2014, el nuevo mapa regional francés de 13 regiones fue aprobado en segunda lectura por 277 votos a favor, 253 en contra y 13 abstenciones. Votaron a favor los socialistas y la mitad del partido progresista (Radicaux de Gauche). El resto de partidos (Front de Gauche, ecologistas, Reublicains y centristas) no respaldó el texto legislativo. En el verano del año siguiente, a la hora de votar el proyecto sobre el nuevo reparto competencial, los ecologistas se sumaron a los socialistas en su respaldo al texto legislativo, pero el resto de partidos continuó expresando su rechazo. Esos resultados ponen de manifiesto la debilidad política del proceso de reformas. Un proceso que puede verse interrumpido o incluso revertido en función del resultado de las elecciones presidenciales y legislativas previstas para este 2017. 
LABURPENA: Azken bost urteetan errepublika frantsesaren lurralde-arkitekturan egin diren erreformak aztertzen ditu artikuluak. Erreforma horiekin, eskualdeak indartu nahi izan dira, bai beste estatu europar batzuek duten maila kritikoaz hornitzeko horiek, bai lehen departamentuenak ziren hainbat eskumen horiei transferitzeko ere. Bestetik, Frantziako udalerrien zatiketa muturrekoaren arazoa aztertzen da, bai eta udalen arteko lankidetza-formulen bidez horri aurre egiteko modua eta hiri handientzat estatutu berezi bat ezarri izana ere. Erreforma horien guztien esanahia eta irismena erabat ulertzeko, Frantziako deszentralizazio-sistemaren jatorria eta bilakaera ere jasotzen ditu artikuluak.

GAKO HITZAK: Deszentralizazio administratiboa. Ekonomia eskualdekatzea. Lurralde-erreformak. Konstituzionalismo frantziarra.

RESUMEN: El artículo analiza las reformas efectuadas durante los últimos cinco años en la arquitectura territorial de la República francesa en orden a potenciar las regiones y dotarlas de una talla crítica similar al de sus homólogas de otros Estados europeos, así como a transferirles diversas competencias que pertenecían antes a los departamentos. Se examina también el problema de la extrema fragmentación municipal de Francia, y el modo de afrontarlo mediante la potenciación de fórmulas de cooperación intermunicipal y el establecimiento de un estatuto especial para las grandes ciudades. Para una cabal comprensión del significado y alcance de todas estas reformas el artículo contiene también una exposición del origen y evolución del sistema de descentralización francés.

PALABRAS CLAVE: Descentralización administrativa. Regionalización económica. Reformas territoriales. Constitucionalismo francés.

ABSTRACT: The article analyzes the reforms carried out over the last five years in the territorial architecture of the French Republic in order to strengthen the regions and provide them with a critical size similar to those of their counterparts in other European states, as well as to transfer various competences that belonged earlier to the departments. The problem of extreme municipal fragmentation in France is also examined, and the way to deal with it is through the strengthening of intermunicipal cooperation formulas and the establishment of a special statute for large cities. For a full understanding of the meaning and scope of all these reforms the article also contains an exposition of the origin and evolution of the French decentralization system.

KEYWORDS: Administrative decentralization. Economic regionalization. Territorial reforms. French constitutionalism. 